Philosophical Review 120 (1), 2011, 43-95

\title{
On imagism about phenomenal thought
}

\author{
Pär Sundström \\ Umeå University
}

\begin{abstract}
Imagism about Phenomenal Thought is (roughly) the view that there is some concept $Q$ (for some sensory quality Q) that we can employ only while we experience the quality Q. I believe this view is theoretically significant, is or can be made intuitively appealing, and is explicitly or implicitly accepted by many contemporary philosophers However, there is no good reason to accept it. Or so I argue.
\end{abstract}

\section{Introduction}

Sensory experience - in its various forms - certainly makes important contributions to our cognitive lives. By sensory experience I gain new information about my environment. But even to the extent that I already know what my environment is like, sensory experience can help me recall it. For example, I know many features of the scene outside the window in front of me. But if I wish to report what I already know, I will be able to do so more quickly and more reliably if I look out the window. And, if I lack the opportunity to look, I may well be better at describing what's out there if I visualize it and let the images guide my report.

In these cases, perception and visualization help me select, among various things I can report or believe or think, true things to report or believe or think. It's a separate question what role such experiences might play in enabling us to believe or report or think things at all, whether truly or falsely. On some views, experience plays an important role here too. For example, according to a concept empiricist view, which appears to be Hume's, we can think and believe only what we have experienced, and combinations of what we have experienced (Hume 1739, book 1, part 1, sect. 1). Hume also seems to subscribe to an imagistic view according to which thinking something at a time consists in undergoing a kind of sensory process at that time. To 
think, believe and reason is, says Hume, to have ideas in the mind that resemble perceptual impressions "in every other particular, except their degree of force and vivacity" (ibid.).

My present concern is a limited kind of imagistic view, which has been rather prominent in recent philosophy of mind. I will formulate the view as follows:

Imagism about Phenomenal Thought: There is a concept $Q$ (for some sensory quality-type Q) such that human subjects occasionally employ $Q$ and, necessarily: if a subject $\mathrm{S}$ employs $Q$ at a time $\mathrm{t}$, then $\mathrm{S}$ experiences $\mathrm{Q}$ at t.

'Concept' is here used in what I shall call the noncommittal sense. To say that someone employs a concept in this sense is just to say that the person thinks something. And to say that a person employs one concept rather than some other concept is just to say that the person thinks one "thing" rather than something else. I shall now and then use the term 'content' for what we think when we think. In that terminology, to say that someone employs a certain concept is to say that the person thinks a certain content, and Imagism about Phenomenal Thought is the claim that there is a familiar content (concerning some sensory quality) that we can think only while we experience that quality. ${ }^{1}$

Imagism about Phenomenal Thought is limited in two obvious respects. First, it concerns thinking about a restricted range of properties, namely sensory qualities, like blue and pain. Second, it claims only that there are some concepts of these qualities that one can employ only while one experiences the relevant quality. The thesis allows that there are other sensory quality concepts the employment of which is not constrained by what one experiences at the time of thinking. Suppose for example that my concept Aunt Brenda's favorite quality happens to be a concept of the quality

\footnotetext{
${ }^{1}$ I don't mean to burden Imagism about Phenomenal Thought with any serious ontological commitment to "objects" of thought. Phrases like 'there is some content that we can think only when...' should here be understood as stylistic variants of colloquial and theoretically uncommitted speech like 'there is something we can think only when ...'. I take these phrases to be compatible with a variety of theoretical views, including ones that avoid ontological commitments to objects of thought. For more on this, see section 2.4 .
} 
blue. Imagism about Phenomenal Thought allows that I can employ that concept without experiencing blue.

I think it's possible to sell Imagism about Phenomenal Thought, thus understood, as an intuitively appealing view. Suppose I attend to a blue quality in my visual field. It seems (to me) plausible that I can apply an act of thinking to the content of my experience; that is, think exactly what I experience. And it might be intuitive to suppose that what I think in such a case is something I can think only while I experience the relevant quality.

In addition, I believe Imagism about Phenomenal Thought is both a theoretically significant view, and a view that many contemporary philosophers explicitly or implicitly accept. As we shall see, there is also an argument - the "recognition argument" (section 3.6 below) - that might at least appear to support the view. However, I shall argue that there is no good reason to accept Imagism about Phenomenal Thought.

Section 2 deals with preliminaries. It specifies and explains the claim of Imagism about Phenomenal Thought (2.1-2.4), clarifies its relations to a pair of look-alike views (2.5), spells out what I will and won't assume $(2.4,2.6)$, cites some endorsements of Imagism about Phenomenal Thought in the literature (2.7), and articulates some of the view's theoretical significance (2.8). Section 3 assesses the view and argues that there is no good reason to accept it. Section 4 wraps up and outlines a slight extension of the argument.

I have found it necessary to be quite explicit at many points in the discussion. As a consequence, the paper is long. But there is a short-cut. Reasonably advanced readers should be able to pick up central parts of the argument from section 2.4, the first part of section 3.4 (the cut-off point is signaled in the text), and section 3.6, and consult the rest á la carte.

A terminological point: As we shall see shortly, the formulation I have given of Imagism about Phenomenal Thought is ambiguous between different views. But I shall not take 'Imagism about Phenomenal Thought' to be ambiguous between these 
views. 'Imagism about Phenomenal Thought' does not denote the ambiguous formulation, but the view that I shall presently explain and contrast with other views.

\section{Preliminaries}

\subsection{Experience}

'Experience' will here be used in a broad sense that covers veridical perceiving as well as a variety of self-generated mental events. In the present sense, you experience the sensory quality red if you veridically perceive a ripe tomato in broad daylight, or if you hallucinate a ripe tomato in broad daylight, or even if you just visualize a ripe tomato basking in broad daylight.

One important restriction will be imposed, however: I shall take experiences to be necessarily conscious. Subpersonal, unconscious processes are not experiences in the present sense, even if they are realized in sensory areas of the brain. As it happens, I doubt that we have reason to believe that there is some familiar sensory quality concept $Q$ that we can employ only while we consciously or unconsciously sense the quality $\mathrm{Q}$, but to consider that view would require an even longer paper than the present one.

\subsection{Necessity}

Many philosophers who accept Imagism about Phenomenal Thought accept, I believe, a view that is unqualified with regard to its necessity. According to this view, there is a concept $Q$ (for some quality $\mathrm{Q}$ ) that we sometimes employ and that no possible thinker could employ without experiencing Q. I believe there is no reason to accept this unqualified view. But I shall take issue with a weaker view. Imagism about Phenomenal Thought, as understood here, is the anthropological thesis that there is a concept $Q$ (for some quality $\mathrm{Q}$ ) that we sometimes employ and that we, as a matter of human psychological necessity, can't employ without experiencing Q. (When I 
henceforth discuss what we cognitively "can" and "can't" do in certain situations, these terms should, unless otherwise noted, be taken to express human psychological possibility and impossibility) This anthropological thesis allows that thinkers with other cognitive capacities - Martians, say - could employ the relevant concept without having the relevant experience, and is to that extent weaker than the unqualified view. $^{2}$ If - as I shall argue - there is no reason to accept the weaker, anthropological view, there is, a fortiori, no reason to accept the stronger, unqualified view either.

\subsection{Familiar concepts}

Imagism about Phenomenal Thought concerns concepts that are familiar to us in the sense that we "occasionally employ" them. Without this restriction, the thesis would be less interesting, because it could then be satisfied by concept employment that is not imagistic at all, in any intuitive sense. Thus, suppose there is a concept (for some sensory quality Q) that we, as a matter of psychological necessity, can't employ at all (because it's too complicated, say). Regardless of the character of this concept, it would then be true that there is a concept of $\mathrm{Q}$ that, as a matter of psychological necessity, if any of us employs it then she experiences Q. This would be true simply on the grounds that, as a matter of psychological necessity, none of us ever employs Q.

2.4 The noncommittal use of 'concept', some theoretical options for the imagist about phenomenal thought, and the individuation of concept employment

To say that someone "employs a concept" in the present, noncommittal sense is, to repeat, just to say that the person thinks something. I believe this is one familiar sense

\footnotetext{
${ }^{2}$ I shall understand the modal claim to allow for extraordinary exceptions, for example, that a human subject could employ the relevant kind of concept without having the relevant kind of experience if her cognitive capacities were, miraculously or through brain transplants, transformed into those of Martians. That's to say, such an exception would not falsify Imagism about Phenomenal Thought, and I will not appeal to anything extraordinary to argue that we lack reason to accept the view.
} 
of the multiply ambiguous term 'concept'. ${ }^{3}$ It is noncommittal in that, to say that someone employs a concept in this sense is not to assume or presuppose any particular view about what's involved in thinking, nor any particular view about what we think when we think.

This means that Imagism about Phenomenal Thought, as I understand it here, is a very generic view which is susceptible of many specifications. It's worth illustrating the available variety of specifications.

In the plainest possible English, Imagism about Phenomenal Thought says that there is something we can think only while we have a certain experience. Now, there is a wide variety of views about what it is that we think when we think. On one view, what we think are always propositions. If you combine this view with Imagism about Phenomenal Thought, you get the view that there is some proposition that we can think only while we have a certain experience. There is again a wide variety of views about what propositions might be. For example, some hold that propositions are functions from possible worlds from truth-values. ${ }^{4}$ If you combine that proposal with Imagism about Phenomenal Thought and the view that what we think are always propositions, you get the view that there is some function from possible worlds to truth-values that we can think only while we have a certain experience. Generally, if you combine Imagism about Phenomenal Thought with the proposal that what we think are always propositions, and that propositions are objects of type $\mathrm{X}$, you get the view that there is some object of type $\mathrm{X}$ that we can think only while we have a certain experience. ${ }^{5}$

There are both "limited" and "global" challenges to the suggestion that what we think are always propositions. On a limited note, one may hold that, while we sometimes think propositions, we sometimes think just $\operatorname{dog}$ (say), without thinking that Fido is a dog, or anything else expressible by a "that-clause". If you combine that proposal

\footnotetext{
${ }^{3}$ See the next section for a pair of other, also familiar senses of the term.

${ }^{4}$ See Stalnaker 1984.

${ }^{5}$ One may also hold that we sometimes or always think more than one type of proposition; for example, both a function from possible worlds to truth-values and a structured proposition composed of Fregean Sinne. If you combine that view with Imagism about Phenomenal Thought and the proposal that what we think are always propositions, you get the view that there is some proposition of either of these kinds that we can think only while we have a certain experience.
} 
with Imagism about Phenomenal Thought, you get the view that there is either some proposition or some non-propositional object that we can think only while we have a certain experience. On a global note, one may urge that we never think propositions. For example, according to one "adverbialist" view, to think that $p$ is a matter of thinking in a certain way ("that p-ly"), rather than a matter of standing in the thinking relation to the proposition that $p .{ }^{6}$ I take Imagism about Phenomenal Thought to be combinable with this kind of as well. The combination entail that there is a certain "Q-ly" way of thinking that we can engage in only while we experience the quality Q.

Since my interest here is in the generic view, which can be specified in such different ways, I will remain neutral on whether what we think should be understood in terms of propositions of one kind or other, in terms of non-propositional objects, adverbially, or in some other way. I shall argue that there is no reason to accept Imagism about Phenomenal Thought regardless of what view one has on this issue.

While I shall remain neutral about what we think when we think, I shall operate on an assumption that is connected to this issue. I call it the Nonreferentialist assumption. The assumption is that I may employ different concepts - that is, think different "things" - in two acts of thinking even if these thinkings concern exactly the same objects and properties and the same "ordering" of them (for example, if they attribute

\footnotetext{
${ }^{6}$ For this kind of view, see Tye 1989, and for a close kin, Armstrong 1973, sect. 4.3-4.4.

${ }^{7}$ So, I recognize a wide variety of candidates for what we think when we think, and, consequently, a wide variety of specifications of Imagism about Phenomenal Thought. The purpose of this is, of course, to establish a very general result. However, there are limits to the generality, and one in particular that deserves mention: I shall take it that mental symbols - for example, symbols in a "language of thought" - are not candidates for what we think when we think. Consequently, the view that there is a type of mental symbol that we can use only while we have a certain experience is not a specification of Imagism about Phenomenal Thought. (This is not to rule out that we think with mental symbols. It's just to say that, whether or not we do, they are not what we think when we think.) I believe this is a natural limitation. The view that thinking is a relation between a subject and proposition of one kind or other, and the adverbial theory, are both theories about how we should understand the "objects" of thought: they say either that the "objects" of thought really are objects and say what kind of objects they are, or that these things are not really objects but should be understood in some other way. In contrast, I take the view that we think with mental symbols to not be a view about the "objects" of thought at all, but rather a view about how we "grasp" or "determine" whatever it is that we think when we think. This also seems to be how mental symbol theorists themselves - or many of them anyway - view the matter (see for example Field 1978; Fodor 1978, 60; 1987, 17; 1994, 47; and Prinz 2002, sect. 1.2.2). Some may still not see the dividing line I'm drawing here to be as natural as I do. I will to some extent accommodate this potential disagreement by saying a few things about the view ("Mental Symbol Imagism") that there is a type of mental symbol that we can use only while we have a certain experience (see sections 2.5 and 3.9).
} 
exactly same properties to the exact same objects). ${ }^{8}$ The Nonreferentialist assumption is compatible with some but not all views about what we think when we think. For example, it is compatible with the view that we think propositions composed of Fregean Sinne, and with an adverbial construal of thinking. But it is not compatible with the view that we think sets of possible worlds or functions from possible worlds to truth-values (and nothing more ${ }^{9}$ ), or with the view that we think "Russellian propositions" composed of objects and properties (and nothing more). On these accounts, I necessarily employ the same concepts - that is, think the same "things" as long as I attribute the same properties to the same objects, or otherwise think about the same objects and properties in one and the same ordering.

The reason for operating on the Nonreferentialist assumption is that I take it to be concessive towards Imagism about Phenomenal Thought. To see why, consider for a moment the contrary, Referentialist assumption that I necessarily employ the same concepts as long as my thought concerns the same objects and properties in the same ordering. If one wants to defend Imagism about Phenomenal Thought against the background of this assumption, it seems one must make plausible that there is some sensory quality that my thought can concern at all - for example, that I can attribute to some object, or attribute some property to, or just think about all by itself - only while I experience that quality. Because if (i) there is something I can think only while I experience a certain quality, and (ii) what I think is the same as long as my thought concerns the same objects and properties and ordering of them, it follows that (iii) there is some object or property or ordering of objects and properties that my thought can concern only while I experience a certain sensory quality. And presumably, (iii) is true only if (iv) there is some sensory quality that my thought can concern at all only while I experience that quality. ${ }^{10}$ Now, while it's too early to take

\footnotetext{
${ }^{8}$ The idea that our thoughts "concern" objects and properties and attribute the latter to the former fits more or less naturally, it seems to me, with different views about what we think when we think. (Less naturally, for example, with adverbialism.) But I shall assume that one can somehow or other make sense of this (very natural) idea on all such views.

9 "And nothing more", because the Nonreferentialist assumption is compatible with a "combination view" according to which we think both Fregean propositions and functions from possible worlds to truth-values (cf. footnote 5 above).

${ }^{10}$ Besides (iv), there are only two possible accounts of (iii): One is that (v) while my thought can concern any object and property whether or not I have a certain experience, there is some ordering of objects and properties I can think only while I have a certain experience. The other is that (vi) there is some sensory quality that I must experience in order for my thought to concern some object or property other than that quality. It seems clear that neither (v) nor (vi) is a live option.
} 
a definite stand on the issue, it at least seems hard to defend (iv); on the face of it, my thought can concern any sensory quality at a time without my experiencing that quality at that time. For example, as I right now focus on the off-white background color of this word-processing document, I think to myself that - as I may put it - that light blue color quality that I normally experience when I look at my desktop is pretty. It is natural to suppose that, when I think what I just indicated, my thought concerns a certain light blue sensory quality. But I didn't experience that light blue quality at that time; I experienced off-white. ${ }^{11}$

If, on the other hand, one wants to defend the combination of Imagism about Phenomenal Thought and Nonreferentialism, one can readily allow that my thought can concern any sensory quality at a time without my experiencing it at that time. Imagism about Phenomenal Thought says only that there is $a$ concept (concerning some quality Q) the employment of which requires a simultaneous experience of Q. Given the Nonreferentialist assumption that I may employ different concepts in two acts of thinking even though these thinkings concern the same objects and properties in the same ordering, this claim obviously allows that there is some other concept concerning Q the employment of which does not require a simultaneous experience of Q.

Thus, it seems to be clearly easier to defend Imagism about Phenomenal Thought given Nonreferentialism than given Referentialism. Hence, if I can make plausible that there is no reason to accept Imagism about Phenomenal Thought against the background of the Nonreferentialist assumption, it appears safe to generalize to the conclusion that there is no reason to accept it period.

The issue between Referentialism and Nonreferentialism concerns a (purported) sufficient condition for concept employment sameness: Referentialism claims, and

\footnotetext{
${ }^{11}$ Someone might suggest that, when I think what I just indicated, my thought doesn't concern a particular quality, but rather a second-order property of a quality, namely the property of being a quality that I normally experience when I look at my desktop. But if this is one's reaction, one should consider the following. If my thought can thus concern a second-order property of a sensory quality (without my experiencing that quality), it seems plausible - at least prima facie - that I can find some way of directing my mind, via the second-order property as it were, to the sensory quality itself (without experiencing it). For example, I may introduce a name for the quality, along these lines: There is a particular quality that I in fact normally experience when I look at my desktop. Call it ' $B$ '. Now, B is pretty.
} 
Nonreferentialism denies, that I necessarily employ the same concepts whenever my thought concerns the same objects and properties in the same ordering. We also need to attend to the reverse issue of sufficient conditions for concept employment difference.

The Nonreferentialist assumption - that I may employ different concepts in two acts of thinking even if I attribute exactly the same properties to exactly the same objects in these two acts - is compatible with any number of proposals about the conditions under which I do employ different concepts (think different "things") in two thinkings. I shall try to make plausible that Imagism about Phenomenal Thought is indefensible on any view on this issue that is worth taking seriously.

There is a rather limited number of views on this issue that have been widely taken seriously in philosophy. I can think of two suggestions - or, rather, two families of suggestions - that are relevant for present purposes. The first is that concept employment is distinguished by some Fregean cognitive significance test or other. One example of such a test is the following:

CS1: A thinker S employs different concepts of a quality Q in two acts of thinking $\mathrm{T} 1$ and $\mathrm{T} 2$ if (a) it is possible for $\mathrm{S}$ to rationally believe what she thinks in T1 while doubting what she thinks in T2, or vice versa and (b) there is no difference in what $\mathrm{S}$ thinks in $\mathrm{T} 1$ and $\mathrm{T} 2$ other than what concepts of Q she employs. ${ }^{12}$

The second suggestion is that concept employment is distinguished by some kind of holistic test or other. ${ }^{13}$ I shall argue that Imagism about Phenomenal Thought can't be defended given either of these two types of test. ${ }^{14}$

\footnotetext{
${ }^{12}$ This test more or less resembles tests formulated by Evans $(1982,18)$, Campbell $(1987,284)$, Peacocke (1992, 2), Chalmers (2002, sect. 2), and Brown (2004, 197). For unusually explicit presentations and discussions of the motivations for distinguishing concept employment in this way, see Boghossian 1994 (who endorses the motivations), and Brown 2004 (who resists them).

${ }^{13}$ For an unusually explicit (critical) presentation and discussion of the motivations for distinguishing concept employment along these lines, see Fodor and Lepore 1992, 22-32.

${ }^{14}$ There are tests other than these that are widely taken seriously in philosophy, but that offer little or no encouragement for an imagist about phenomenal thought and are therefore less relevant here. One example is (the Reference Test) that I employ different concepts (think different things) in two thinkings if there is some difference in what objects or properties or ordering among objects and properties these thinkings concern. To use this test to justify Imagism about Phenomenal Thought one
} 
One might perhaps think that - whether or not this is customary - we should be very pluralistic about tests for concept employment distinctness, and that there is sure to be some test, which can be motivated for some purpose or other, and against the background of which there will be reason to accept Imagism about Phenomenal Thought. I will consider this suggestion too. I believe it is incorrect. My ambition is to make plausible that any test for concept employment distinctness is such that either (i) Imagism about Phenomenal Thought can't be defended against the background of it, or (ii) the test itself is not well-motivated, or (iii) both.

\subsection{Two other senses of 'concept' and two other imagistic theses}

The noncommittal sense of 'concept', and the present imagistic thesis which I have explained partly in terms of it, should be distinguished from at least two other senses of 'concept' and two other imagistic theses.

On one view, thinking involves the instantiation of mental symbols in a "language of thought". 'Concept' is often used to refer to such presumed mental symbols (see for example Fodor 1975, 1998). This sense of 'concept' differs from the noncommittal one. To say that someone "employs a concept" in the noncommittal sense is just to say that the person thinks something, whereas to say that someone "employs a concept" in this second sense is to commit oneself to the view that thinking involves the use of mental symbols in a language of thought.

If we plug the mental symbol-understanding of 'concept' into the above formulation of Imagism about Phenomenal Thought, we get a second view, which is distinct from the one that is our concern here. This second view can also be phrased thus:

would have to make plausible that there is some object or property or ordering among such that my thought sometimes concern while I experience a certain sensory quality but can't concern when I don't. As I illustrated above, this is implausible. 
Mental Symbol Imagism: There is a type of mental symbol 'Q' such that human subjects occasionally use tokens of 'Q' to think about a sensory quality-type $\mathrm{Q}$ and, necessarily: if a subject $\mathrm{S}$ uses a token of 'Q' at a time $\mathrm{t}$ then $\mathrm{S}$ experiences $\mathrm{Q}$ at $\mathrm{t}$.

It should be clear that, absent further assumptions, Imagism about Phenomenal Thought and Mental Symbol Imagism are not just distinct, but also independent: neither entails the other. It's conceivable that: there is a content (concerning some quality Q) that we can think only while we experience Q but there is no type of mental symbol that we can think (about Q) with only while we experience Q; indeed, it's conceivable that the former is the case and that thinking does not involve the use of mental symbols at all. ${ }^{15}$ Conversely, it's conceivable that there is a type of mental symbol that we can think with only while we experience Q but not the case that there is some content (concerning Q) that we can think only while we experience Q. For example, it's conceivable that some human subject can employ two different types of term in her language of thought, $\mathrm{T} 1$ and $\mathrm{T} 2$, that both express one and the same content $C$ (concerning some sensory quality $\mathrm{Q}$ ), and one of $\mathrm{T} 1$ or $\mathrm{T} 2$ is such that it is possible to think with it only while one experiences $\mathrm{Q}$ whereas the other can be employed even when one does not experience $\mathrm{Q}{ }^{16}$

I will make some remarks, in section 3.9, about the prospects for defending Mental Symbol Imagism. But this view is not my main concern. For the time being, it is only important to not confuse this view with Imagism about Phenomenal Thought.

There is a third sense of 'concept' that we should take note of as well. The term is sometimes used to refer to constituents of Fregean Thoughts, or "Sinne". ${ }^{17}$ If we plug this third sense of 'concept' into our formulation of Imagism about Phenomenal Thought, we get a third thesis, which can be phrased thus:

\footnotetext{
${ }^{15}$ This is Thau's view. Thau denies that we think with mental particulars (2002, sect. 2.6), but endorses Imagism about Phenomenal Thought (see below, section 2.7).

${ }^{16}$ One may note, though, that there are assumptions, which may not be unnatural or uncommon to make, and that guarantee that Imagism about Phenomenal Thought and Mental Symbol Imagism have the same truth-value. For example, this is so if (i) we do think with mental symbols, and (ii) the contents we think and the mental symbols we think with individuate in exactly the same ways. (Sufficiently interested readers will be able to confirm this equivalence.)

${ }^{17}$ For the third use of 'concept', see for example Peacocke 1992. The three senses of 'concept' - or something much like them - are distinguished by Byrne (2004, sect. 1.1).
} 
Imagism about Phenomenal Fregean Thought: There is a Fregean Thoughtconstituent $Q$ (for some sensory quality $\mathrm{Q}$ ) such that human subjects occasionally think $Q$ and, necessarily: if a subject $\mathrm{S}$ thinks $Q$ at a time t, then $\mathrm{S}$ experiences $\mathrm{Q}$ at $\mathrm{t}$.

The relation between this view and Imagism about Phenomenal Thought should be clear from what was said in section 2.4 above. Fregean Thought-constituents are candidates for what we think when we think. Imagism about Phenomenal Fregean Thought is therefore one version of Imagism about Phenomenal Thought. This means that if, as I shall argue, there is no reason to accept Imagism about Phenomenal Thought, there is a fortiori no reason to accept Imagism about Phenomenal Fregean Thought.

\subsection{Imagistic, full-blooded imagistic, and nonimagistic acts of thinking}

It is clear that that thinking and experiencing can be "connected" with one another at least to this extent: I can think about a given sensory quality while I experience it and be intensely aware that the quality I think about is the same as the quality I experience.

Here's a suggestion that goes beyond this observation: Sometimes when I think about a currently experienced sensory quality and am aware that the quality I think about is the quality I experience, I in some sense use the experience - or the quality - to think about the quality. That's to say, the processes are not just parallel processes between which I notice a connection; the experience somehow enables or even contributes to constituting the thinking.

Should we accept this latter suggestion? I don't have a stake in this issue (nor a firm conviction), but I shall allow that there may be cases where one somehow "uses" an experience of a quality - or the quality itself - to think about that quality. I will call such (purported) acts of thinking full-blooded imagistic thinkings. 'Imagistic thinking' will be used more broadly (and somewhat loosely), for any kind of thinking where 
there is some kind of close connection between a thinking and a simultaneous experience; as, for example, when I am intensely aware that the quality I think about is the quality I currently experience. A nonimagistic thinking is a thinking that is not imagistic. $^{18}$

It should be clear that, even if there are full-blooded imagistic acts of thinking, Imagism about Phenomenal Thought need not be true. Imagism about Phenomenal Thought is true if (i) we occasionally engage in full-blooded imagistic thinking concerning some quality Q, and (ii) what is thought in some such act is impossible for us to think if we don't experience Q. But (ii) does not follow from (i). It might be that I sometimes think some content concerning some quality Q by "using" an experience of Q, but that I sometimes think the same content without using an experience of $\mathrm{Q}$ - or at least that I could do so. The same goes, of course, for (nonfull-blooded) imagistic thinking. ${ }^{19}$

\subsection{Imagism about Phenomenal Thought in the literature}

Imagism about Phenomenal Thought is, I believe, a view that many philosophers accept, either explicitly or implicitly. The following is an almost explicit endorsement by Michael Thau:

\footnotetext{
${ }^{18}$ There are cases where one thinks about a quality while experiencing it, but that are not cases of imagistic thinking as presently understood. For example, I may think that I need to do white laundry while resting my eyes on a white wall without making or noting any connection between the quality I experience and the quality I think about. But for present purposes, I think we can disregard these cases. The reason is the following. While our present concern is whether there is a simultaneous-experience requirement on a certain concept employment, it is overwhelmingly plausible that this is so only if there is a, in the present sense, imagistic requirement. To appreciate this, consider the case where you think about your white laundry without making or noting any connection between the whiteness thought about and a whiteness simultaneously experienced. Since you can apparently employ the relevant sensory quality concept here without in any way "connecting" with the experience, it is overwhelmingly plausible that the experience does nothing to enable this concept employment; it is a mere accidental accompaniment and you could easily have employed the same concept without it. It is therefore hard to see that this kind of case can play any interesting role in the present context. And if we disregard it, thinking imagistically about a quality $\mathrm{Q}$ is co-extensive with thinking about $\mathrm{Q}$ while experiencing $\mathrm{Q}$, and thinking nonimagistically about $\mathrm{Q}$ is co-extensive with thinking about $\mathrm{Q}$ without experiencing $\mathrm{Q}$.

${ }^{19}$ One might of course think that, while (ii) doesn't follow from (i), there is a convincing argument from (i) to (ii). I discuss this line of argument in section 3.1.
} 
We can sometimes have beliefs that attribute perceptual properties to objects; for example, you can focus on some property visually presented to you and ascribe it to, say, fire engines by using the sentence 'Fire engines have that property' to register the belief. But having a belief that ascribes a perceptual property to an object requires a certain kind of phenomenological episode; that is, it requires that the property be visually (or imaginatively) presented to you $(2002,222)$.

(It is clear enough, I think, that the imagistic requirement here is supposed to concern somehow cognizing - thinking, believing, wondering, etc. - that an object has a "perceptual property" rather than specifically believing this.)

In many cases, ambiguities in terms like 'concept' and 'thought ${ }^{20}$ make it somewhat hard to tell that a given philosopher accepts, or would accept, or is committed to Imagism about Phenomenal Thought. One can discern this only by considering a rather broad context. I will illustrate with one case.

David Papineau claims that one can employ "phenomenal concepts" of experiences only while one undergoes the experiences referred to in these acts of thinking:

exercises of phenomenal concepts have the unusual feature that they use versions of the experiences being referred to in the act of referring to them. When we deploy a phenomenal concept imaginatively, we activate a 'faint copy' of the experience referred to. And when we deploy a phenomenal concept introspectively, we amplify the experience referred to into a 'vivid copy' of itself $(2002,169-70)$.

As we have seen, a statement like this does not necessarily amount to an endorsement of Imagism about Phenomenal Thought. If 'exercising a phenomenal concept' in this passage means only using a phenomenal symbol in a language of thought, then the

\footnotetext{
20 'Thought' is, of course, ambiguous in much the way that 'concept' is. In addition to being used for the past tense of 'think' and as a mass term ("a lot of thought went into the process"), I believe it is sometimes used "noncommittally" for what we think when we think however that is understood. In other cases, it is used for Fregean Thoughts, and in yet other cases for mental symbols that "express" what we think.
} 
passage expresses nothing more than Mental Symbol Imagism (the view that there is a type of mental symbol that we can think with only while we experience the quality that the symbol refers to), and this view does not, absent further assumptions, entail Imagism about Phenomenal Thought (the view that there is a content concerning a quality that we can think only while we experience that quality).

However, if one considers the wider context of the above statement, I think it's clear that Papineau can't reasonably be understood as expressing only Mental Symbol Imagism in the passage above. It may be that, when Papineau talks about constraints on exercising "phenomenal concepts", he means to say, in part, that there are constraints on using certain symbols in a language of thought. But whether or not this is so, I think he can only be understood as (also) claiming that there are constraints on thinking certain contents, where contents are something other than mental symbols. There is evidence for this from several passages; one of them is Papineau's diagnosis of Jackson's $(1982,1986)$ "knowledge argument".

According to Papineau, Jackson's Mary can, in her black-and-white room, come to know all facts about color vision, but her lack of relevant experiences prevents her from acquiring phenomenal concepts of these facts. By stressing that Mary lacks a range of concepts, Papineau means to contrast his diagnosis with the "ability hypothesis". The ability hypothesis also says that black-and-white Mary can come to know all facts about color vision, but it claims that what she lacks is only knowledge how to do certain things, such as visualizing conscious qualities and classifying them on the basis of introspection; she does not, according to this hypothesis, lack any knowledge that something or other is the case. ${ }^{21}$ Papineau urges that the ability hypothesis is an incomplete account of Mary's situation: while Mary lacks certain visualizing and classifying abilities, she also lacks something "of a propositional kind" (2002, 60).

Given this intended contrast with the ability hypothesis, Papineau's claim that lack of relevant experiences prevents Mary from acquiring a range of phenomenal concepts can only be understood, I believe, as a claim to the effect that Mary is unable to think

\footnotetext{
${ }^{21}$ For this view, see Nemirow 1980, 1990; Lewis 1983, 1988; Levin 1986; and Jackson 2003.
} 
certain contents, where contents are something other than mental symbols. This is because, if all Papineau means to say by claiming that Mary lacks "phenomenal concepts" is that she's unable to think with a certain kind of mental symbol, then his view would not be distinct from the ability hypothesis. At any rate, it would not be distinct from that hypothesis as it is understood by its arguably most prominent defender. David Lewis, in the course of defending the ability hypothesis, explicitly grants that Mary may on release acquire a new "word" in a "language of thought" - a word that could not have been added to that language by any means other than experience. (Lewis urges that that would be no more significant than learning a Russian word for what one can already express in English; 1988, 587-8). ${ }^{22}$ On the other hand, if Papineau's claim is that Mary is unable to think certain (non-mental symbol) contents, then his view is distinct from the ability hypothesis. In this case, Mary can on release "mentally express" some (non-mental symbol) content that she could not mentally express before. There is no indication that Lewis or any other defender of the ability hypothesis has been prepared to allow that.

So, when Papineau talks about constraints on exercising, acquiring, or having phenomenal concepts, I think he can only be reasonably understood as talking (at least in part) about constraints on thinking, learning how to think, or being able to think certain (non-mental symbol) contents. That's to say, his claim that we can exercise phenomenal concepts of experiences only while we have these experiences should be understood (at least in part) as the claim that there are certain (non-mental symbol) contents concerning experiences that we can think only while we have these experiences. And this is Imagism about Phenomenal Thought.

Other philosophers who, I think, endorse, would endorse, or are committed to endorsing Imagism about Phenomenal Thought include Andrew Melnyk (2002), David Chalmers (2003), and Katalin Balog (forthcoming a and b). However, as we

\footnotetext{
${ }^{22}$ Papineau takes note of this passage of Lewis', and finds in it "caginess" about whether Mary acquires a new concept on release $(2002,62)$. But I don't see any caginess here. It seems to me reasonable to take the ability hypothesis, as it is intended by its defenders, to rule out that Mary on release learns to think some (non-mental symbol) content that she could not formerly think, while allowing that she acquires a new mental symbol to think with.
} 
have just seen, it often takes some effort to justify this ascription. So I won't try to defend these interpretations here. ${ }^{23}$

\subsection{The theoretical significance of Imagism about Phenomenal Thought}

Imagism about Phenomenal Thought is, it seems to me, an intrinsically interesting thesis about the connection between experience and thought. In addition, it's a view with significant theoretical implications. I shall provide three illustrations.

Imagism about Phenomenal Thought has straightforward implications for the issue of the "privacy" of the mind. Consider someone who is cortically color blind, and so can't perceive or dream about or visualize chromatic colors. ${ }^{24}$ Imagism about Phenomenal Thought implies that there are things concerning other people's experiences that such a person can't as much as think, let alone know to be true.

A related implication of Imagism about Phenomenal Thought concerns the conditions of language and communication. It is somewhat natural to suppose that (i) what I can think I can in principle express in some language. Several influential 20th century philosophers have further argued for views which seem to entail that (ii) to understand a speaker of a language it is never required that one be similar to the speaker in any

\footnotetext{
${ }^{23}$ Views in the vicinity of Imagism about Phenomenal Thought are embraced in the literature as well. John McDowell (1994, lect. 3, sect. 5) suggests that there are demonstrative concepts of specific sensory qualities that we can employ only while we experience the qualities referred to and a short while after (namely, as long as an ability to recognize the relevant quality persists). A similar view is suggested by Brewer (1999, sect. 5.3.1-5.3.2). Michael Tye (1999, 712; 2003, §§ 16-7) claims that a phenomenal concept "disposes" one to form a certain conscious image, or is "apt" to trigger such an image (1999, 712; 2003, §§ 16-7). Loar makes similar suggestions (1990/1997, 600, 605). Ned Block claims that, while phenomenal concepts can be used nonimagistically $(2007,282)$, imagistic uses of them are "fundamental" in that, "No one could have a phenomenal concept if he could not in some way relate the concept to such fundamental uses" (252). At a somewhat greater distance from Imagism about Phenomenal Thought, Barsalou (1999) and Prinz (2002) defend views according to which all human thinking processes involve conscious or unconscious sensory processes. I'm inclined to think that the considerations advanced in this paper: (a) with marginal extensions show that there is no reason to accept McDowell's and Brewer's suggestions; (b) could be developed to question Tye's and Loar's suggestions; and (c) could be developed to question at least some of the arguments that Barsalou and Prinz offer for their views. It is less clear what they say about Block's proposal. On the one hand, some material in section 3.5 suggests a way of developing and defending Block's claim, at least for the case of very specific qualities. But on the other hand, I believe that case - and even the view - might be undermined by some extensions of that material. However, in the interest of space I shall not develop any of this here.

${ }^{24}$ For a case, see Sacks 1995.
} 
conscious, or otherwise "inner", respect; agreement in overt dispositions (and perhaps natural and social habitat) is always sufficient for understanding (see Wittgenstein 1953, §293; Quine 1960, 8, 26; 1990, 37-8; and Dummett 1973, 216). However, Imagism about Phenomenal Thought seems to imply that these two claims - (i) that I can express in some language anything I can think, and (ii) that linguistic understanding is independent of "inner" similarity - can't both be true. Assuming - as seems reasonable - that one can understand an expression only if one can think what it says, it follows from Imagism about Phenomenal Thought that: if it is possible to express in a language anything one can think, then it is possible for a speaker $\mathrm{S}$ to produce a linguistic expression at a time $t$ that can be understood only by those who can have experiences similar enough to those that $\mathrm{S}$ has at $\mathrm{t}$.

Finally, a number of philosophers - including Papineau (1993, 2002, 2007), Melnyk (2002), and Balog (forthcoming a and b) - have invoked Imagism about Phenomenal Thought as part of a "phenomenal concept strategy" for defending mind-body materialism. The general idea, shared by these philosophers, is this. If employing one concept is cognitively sufficiently different from employing another, that can generate an intuition or presumption that these concepts must concern distinct things, whether or not there is a rational ground for so supposing. (Consider for example thinking about myself in a distinctly first-personal way, as "I myself", and thinking about - what turns out to be - myself as "the shopper who set off the alarm".) Suppose now that Imagism about Phenomenal Thought is true. Then I have a concept $Q$ of some sensory quality $\mathrm{Q}$ which is such that, in order to employ $Q$ I must experience Q. Next, take the concepts of neurobiology. For any such concept $N$, it is presumably not a requirement of my employing $N$ that I experience $\mathrm{Q}$. Thus, there is a cognitively striking difference between $Q$ and any concept of neurobiology. Due to this difference between the concepts ( $Q$, and the concepts of neurobiology), I may well have an intuition or presumption that the phenomena $(\mathrm{Q}$, and the phenomena studied by neurobiology) must be distinct, whether or not there is any rational ground for so supposing. That's to say, given Imagism about Phenomenal Thought it seems possible to explain our intuitive resistance to materialism as generated solely by the 
difference between two types of concept of consciousness: one "first-personal" and imagistic, the other "third-personal" and nonimagistic. ${ }^{25}$

If, as I shall argue, there is no reason to accept Imagism about Phenomenal Thought, then, whatever the merits may be of these implications of the view, the view does not provide a good basis for embracing them.

\section{Assessing Imagism about Phenomenal Thought}

I shall now argue that there is no good reason to accept Imagism about Phenomenal Thought. Sections 3.1-3.3 are warm-up exercises. 3.1 and 3.2 set aside a couple of potential distractions. 3.3 highlights the "cognitive component" of imagistic thinking, and outlines one possible explanation of how Imagism about Phenomenal Thought might be false. Sections 3.4 and 3.6 deal with what I take to be the most serious strategies for defending Imagism about Phenomenal Thought on the basis of Fregean cognitive significance tests for concept employment distinctness. Section 3.5 interpolates some positive suggestions about what kinds of nonimagistic thinking might amount to employment of the same concept as an imagistic thinking. Section 3.7 considers whether Imagism about Phenomenal Thought can be defended on the basis of some holistic test for concept employment distinctness, and 3.8 whether it might be defended on the basis of some other kind of test. In 3.9, I make some remarks about the prospects of defending Mental Symbol Imagism.

\section{1 "Ways of thinking"}

I have accepted that concept employment may be individuated according to some Fregean test or other (section 2.4). I have also accepted that there may be full-blooded imagistic acts of thinking: cases where one in some sense uses an experience of a quality - or the quality itself - to think about that quality (section 2.6). It may be

\footnotetext{
${ }^{25}$ For a negative assessment of this strategy for defusing anti-materialist intuitions, see Sundström 2008.
} 
tempting to think that, if this much is accepted there is a quick route to Imagism about Phenomenal Thought.

Suppose I use a current experience of red to think about red, and that I think about the same quality without experiencing it on some other occasion. It would be very apt to say that I on these two occasions think about red in different ways. And, one may wonder, isn't the Fregean view that whenever there is a difference in ways of thinking about red there is a difference in what one thinks? If so, it would follow straightforwardly that there is something that I sometimes think (concerning red) while I experience red and that I can't think if I don't.

The right response to this is, I believe, that it is not the case - even on the Fregean view - that there is a difference in what one thinks whenever there is a difference in ways of thinking about something. For illustration, consider some different ways in which I can think (say) that 15 is the square root of 225. I can think this passingly and casually, but also with focus and concentration. These are different ways of thinking. But the Fregean view does not entail that there must therefore be a difference in what I think in these cases. And therefore, the Fregean view does not entail that any difference in ways of thinking reflects a difference in what is thought. ${ }^{26}$ But then the fact that a full-blooded imagistic thinking and a nonimagistic thinking about red are different ways of thinking about red does not by itself provide a reason to suppose that what is thought in these acts differ. ${ }^{27}$

\footnotetext{
${ }^{26}$ This point is made quite explicitly by Evans: "if the notion of 'a way of thinking about something' is to be elucidatory of Frege's notion of sense, ... [we] must not discriminate ways of thinking of things so finely that no difference of epistemic attitude can rest upon the discrimination. To take an example of Frege's, we must say that someone who thinks of a horse as the horse ridden by the Queen is thinking of the horse in the same way as someone who thinks of it as the Queen's steed, for the difference in poetic colouring could never be the basis, for someone who fully grasped both senses, for taking different attitudes towards the two thoughts" (Evans 1982, 20; the example is from Frege 1918, 63). We find further, analogous examples if we move from acts of thinking to linguistic expressions. I can write a sentence and also utter one. It is apt to say that these are different ways of expressing a linguistic message. But the Fregean view does not entail that there must therefore be a difference in what I linguistically express.

${ }^{27}$ There is another route - or apparent route - from the premise that full-blooded imagistic thinking and nonimagistic thinking are different ways of thinking to the conclusion that Imagism about Phenomenal Thought is true. Consider the adverbialist claim that thinking two different "things" or "contents", C1 and $\mathrm{C} 2$, is a matter of thinking in two different ways, "C1-ly" and "C2-ly". Given this view, it may appear to follow straightforwardly that a full-blooded imagistic and a nonimagistic thinking must be thinkings of different "things". However, I don't think that's true. I don't think any adverbialist would want to say that there is a difference in what I think (as the adverbialist understands this) whenever there is a difference in ways of thinking. For example, I don't think an adverbialist would generally want to distinguish what I think in two acts when I think focusedly in one and passingly in the other.
} 


\subsection{Sensory qualities as themselves parts of thought contents}

As I mentioned in section 1, it seems to me plausible that, while I attend to a blue color quality in my visual field, I can think exactly what I experience. It would seem that, in such a case, the sensory quality itself is a constitutive part of the content of my thinking.

But it should be clear that this suggestion - that a sensory quality can itself be part of a thought content - is different from Imagism about Phenomenal Thought. The former is a claim about how some contents are. Imagism about Phenomenal Thought, on the other hand, is a claim about what it takes to think certain contents.

It should also be clear that even if a quality can be a part of a thought content, that by itself goes no way towards showing or making plausible that one can think that content only while one experiences the quality. It is perhaps easiest to see this if we first consider the view that we think "Russellian propositions": abstract objects composed of concrete objects and properties. It seems clear that, if we sometimes think such contents, then a sensory quality can be a part of a thought content. Indeed, a sensory quality will be part of a thought content whenever my thought concerns a sensory quality. But it is apparent that this by itself goes no way towards showing that I can think that kind of content only while I experience the relevant quality. As illustrated above (section 2.4), it is prima facie very plausible that my thought can concern a sensory quality even though I don't experience the quality at the time of thinking.

What if we think "Fregean propositions": abstract objects composed of abstract Sinne that refer to objects and properties? Can a sensory quality be a part of such a content of thought? That is, can a sensory quality itself be or contribute to constituting a

Rather, I think an adverbialist would want to identify what I think with ways of thinking on a certain individuation of these ways. The same kind of point actually applies in the kind of case that is often supposed to be analogous to mental acting, understood adverbially: I may dance the waltz energetically and lazily; these are different ways of dancing, but they may be dancings of the waltz for all that - even 
Sinn? Perhaps. But again, this by itself goes no way towards making plausible that I can think such a Sinn only while I experience the quality that constitutes it. That a given Sinn is constituted by a quality is quite compatible with the hypothesis that thinking this Sinn may be accomplished by a nonimagistic cognitive act.

\subsection{The cognitive component of imagistic thinking}

Some familiar observations about imagistic thinking provide materials for at least a sketchy explanation of how Imagism about Phenomenal Thought might be false.

As has often been observed, even in cases where thinking is somehow aided by or connected with an experience, what one thinks is not determined by - or not only by what one experiences; it's at least partly determined by how what one experiences is "taken" or "understood". A classic instance of this observation is Wittgenstein's (1953, p. 54) remark that one and the same image can be employed both to think that a man is walking is uphill and that a man is sliding downhill. The phenomenon can be observed in the case of thinking about sensory qualities as well. For example, it would seem that I can use one and the same quality (or experience) both to think about the generic sensory quality red and about a specific shade of red.

These observations suggest that, in order to think something it is never enough that one has a certain experience; some kind of "cognitive act" is always required in addition. Moreover, one's experiences and one's cognitive acts can, at least to some degree, vary independently of one another. When I use one and the same image to think about red and a specific shade of red respectively, my experience remains the same while my cognitive acts differ. Conversely, there seems to be constancy in my cognitive acts when I use two different images to think that a man is walking uphill, or use two different shades of red to think about the generic quality red. These points

if dancing the waltz is a matter of dancing a certain way rather than a matter of standing in the dancing relation to the waltz. 
are standardly accepted, even emphasized, by imagists of various brands, including sympathizers of Imagism about Phenomenal Thought and neighboring views. ${ }^{28}$

But if this much is accepted, one can get a sense of how Imagism about Phenomenal Thought might be false. Take a case where you think some content $C$ concerning some sensory quality $\mathrm{Q}$ while experiencing $\mathrm{Q}$. We have just observed that thinking $C$ in this case requires - on anybody's account - that you engage in a relevant "cognitive act". Now, Imagism about Phenomenal Thought is false if, for any such case, the relevant cognitive act is such that (i) one can engage in it without experiencing $Q$, and (ii) doing so suffices to think $C$. (i) and (ii) would provide an explanation of why Imagism about Phenomenal Thought is false (if it is).

That's of course quite sketchy. One might want to know more about what the relevant kind - or kinds - of cognitive act might be. I shall develop some suggestions on this in section 3.5 below. But before I turn to that, I shall introduce and discuss a "Fregean" strategy for defending Imagism about Phenomenal Thought.

\subsection{Cognitive significance and a crucial observation}

If one supposes that thought contents individuate according to some Fregean cognitive significance test, a natural way to defend Imagism about Phenomenal Thought is the following: take a particular case where someone thinks about some quality Q imagistically, and argue, on the basis of a Fregean test, that it is (at least) psychologically impossible for one of us to think what is thought in this case without experiencing Q. ${ }^{29}$

\footnotetext{
${ }^{28}$ See for example Hume 1739, sect. 1.1.7; Berkeley 1710, §16; Chalmers 2003, sect 3.2, point 2; Block 2007, 283; and Papineau 2007, 115-7, 122-3. By talking about "cognitive acts", I don't mean to rule out that this phenomenon can be partly explained in sensory terms. Imagists can take, and have taken different positions on this. For example, Kant, whom I take to be a kind of imagist, takes cognitive acts to be entirely nonsensory in nature (1781, A51-2/B75-6). By contrast, Hume explains them partly in sensory terms $(1739,1.1 .7)$.

${ }^{29}$ Recall that Imagism about Phenomenal Thought is the anthropological thesis that there is a familiar concept that we, as a matter of human psychological necessity, can't employ unless we have a certain experience; see section 2.2.
} 
I hope to make plausible, in this section and section 3.6, that there are no prospects for a successful argument along these lines. The aim of this section is to show that there is, at best, a small space for such an argument. In 3.6, I hope to show that the space left open by this section is not a fertile ground for the argument either.

There is an observation that, I believe, (i) ought to be uncontroversial at least for the case of thinkings concerning fairly generic sensory qualities, like red and bluish-red, and that (ii) prevents the present line of argument from being successful for any quality to which it applies. It is this:

Observation: In any case where some normally functioning human subject thinks about some (fairly generic) sensory quality $Q$ while experiencing Q, it is psychologically possible for the person to (a) also think (say, a moment later) about $\mathrm{Q}$ without experiencing $\mathrm{Q}$, and (b) have transparent and immediate knowledge that she's thinking about the same quality in these two acts.

By saying that we can have "transparent and immediate" knowledge in this kind of case, I mean to say that we can have knowledge that is no more fallible or inferential than the best knowledge any of us can ever have that two thinkings concern the same thing. Compare for example a case where I think to myself what I would find natural to express as 'Detroit is an American city', and an instant later make the effort to think the same thing again. In the typical such case, I don't need to go through any mental step - at any rate, no introspectible mental step - to arrive at the judgment that I think about the same object, the city of Detroit, twice. Moreover, such a judgment can typically not easily go wrong. Observation claims that, whenever someone thinks about some (fairly generic) quality while experiencing it, it is possible that: she also thinks about that quality without experiencing it and has this kind of knowledge that the two mental acts concern the same quality.

Before I spell out why I think Observation is true, and how it blocks the present line of argument for Imagism about Phenomenal Thought, let me say a word about the qualification that Observation is true at least for thinking concerning fairly generic sensory qualities. The qualification is motivated more by rhetorical strategy than by 
real doubt. I am inclined to think that Observation is true without the qualification. But I expect that many philosophers would doubt this. (Doubts about whether Observation is correct in the case of highly specific qualities may arise from the consideration that it seems intuitively hard to hold such qualities "in mind" in the absence of experiences of them, and/or from evidence that we are poor at reidentifying such qualities over time; cf. Chalmers 2003, sect. 3.2). And I have limited hope of neutralizing such doubts - at least at this stage. So, for strategic reasons, I propose to temporarily set specific qualities aside. I shall in this section try to make plausible that Observation is correct for the case of fairly generic sensory qualities, and then show how that blocks the present line of argument for Imagism about Phenomenal Thought for these cases. In section 3.6, I shall consider whether Imagism about Phenomenal Thought can be defended by appeal to very specific sensory qualities. I will say some things there in favor of accepting Observation for that case, but I will not rely very heavily on this.

Why, then, do I think Observation is true (for the case of fairly generic qualities)? My confidence is ultimately based on reflection on my own case. In every case that I have reflected on, $I$ have, as far as I can tell, been able to (i) follow an act of thinking about some (fairly generic) quality $\mathrm{Q}$ that is accompanied by an experience of Q with a thinking about $\mathrm{Q}$ that is not so accompanied and (ii) have the described kind of transparent and immediate knowledge of the co-reference of these two thinkings. Assuming that there is nothing special about the cases I have reflected on, I have generalized to the conclusion that it is possible for me, in every case where I think about some (rather generic) quality Q while experiencing it, to follow this thinking with a thinking about $\mathrm{Q}$ that is unaccompanied by an experience of $\mathrm{Q}$ and have the described kind of knowledge about the co-reference of these two acts. Assuming further that there is nothing special about me in this respect, I have generalized to the conclusion that any normally functioning human subject can follow an act of thinking about some quality $\mathrm{Q}$ that is accompanied by an experience of $\mathrm{Q}$ with a thinking about $\mathrm{Q}$ that is not accompanied by that experience and have the described kind of knowledge of the co-reference of these two acts. I can't see that this conclusion can reasonably be doubted, and I shall henceforth assume that it is true. 
I shall also assume - what should be uncontroversial - that if it can be transparently and immediately clear to a subject that she's thinking about the same quality in two acts of thinking, it can also be transparently and immediately clear to her that she attributes this quality to the same object in the two thinkings, or that she attributes the same property to this quality twice over. For example, if someone attributes to the quality red, while experiencing it, the property of being Aunt Brenda's favorite quality, then she can (say, a moment later), without experiencing red, attribute this property to red again, and have transparent and immediate knowledge, not just that she is thinking about the same quality, but also that she attributes the same property to it, in the two acts.

Let's now return to the strategy for defending Imagism about Phenomenal Thought that I outlined above. The strategy had two steps. The first was to focus on some case where one thinks imagistically about some quality. So pick a case where you find it most plausible that you think some content that concerns some (fairly generic) sensory quality Q and that you can think only while you experience Q. Call the chosen act of thinking TW ("W" for well-chosen). The second step was to argue on the basis of some Fregean cognitive significance test that what is thought (concerning Q) in TW is at least psychologically impossible to think without experiencing Q.

Given that Observation is correct, I don't think there is any chance of justifying the second step. Consider, to begin with, the cognitive significance test formulated above:

CS1: A thinker S employs different concepts of a quality Q in two acts of thinking $\mathrm{T} 1$ and $\mathrm{T} 2$ if (a) it is possible for $\mathrm{S}$ to rationally believe what she thinks in T1 while doubting what she thinks in T2, or vice versa and (b) there is no difference in what $\mathrm{S}$ thinks in $\mathrm{T} 1$ and $\mathrm{T} 2$ other than what concepts of Q she employs.

By Observation and what is safe to assume given Observation, there is a (psychologically) possible case where the subject of TW (i) thinks about Q without experiencing Q, and (ii) has transparent and immediate knowledge both that she thinks about the same quality and that she attributes it to one and the same object, or 
attributes one and the same property to it, in these two acts. But then it seems that she can't rationally believe what she thinks in TW while doubting what she thinks in this nonimagistic companion of TW, or vice versa. And then CS1 does not distinguish the sensory quality concepts that she employs in these acts. And therefore, CS1 can't be used to show that what is thought in TW is psychologically impossible to think without experiencing Q.

It would not be unreasonable, I think, to be convinced by these considerations alone that Observation blocks the present line of argument for Imagism about Phenomenal Thought for the case of generic sensory qualities - and whatever other qualities Observation may apply to. Whoever is thus convinced may want to proceed to the next section. Those who are not may choose to read the remainder of this section.

CS1 is one "cognitive significance" test for concept employment distinctness. Might there be some other such test that (i) distinguishes the concept employment of TW from the concept employment of a nonimagistic companion of TW where the subject has transparent and immediate knowledge that she is thinking about the same things in the two acts, and that (ii) thereby provides support for Imagism about Phenomenal Thought?

CS1 tests for distinctness of concept employment by considering one subject of two thinkings and whether it's possible for that subject to rationally believe one thing she thinks while doubting the other. Call this kind of test a Single Subject Test for Concept Employment Distinctness. Now, one could also - or so it may seem - test for concept employment distinctness by considering one subject of two thinkings and whether it is possible for some subject - which need not be identical to the subject of the thinkings - to believe one of the things that the first subject thinks while doubting the other. Let's call this kind of test a Multiple Subject Test for Concept Employment Distinctness. Here is one version: 
CS2: A thinker S employs different concepts of a quality $Q$ in two acts of thinking $\mathrm{T} 1$ and $\mathrm{T} 2$ if (a) it is possible for some subject $\mathrm{S}^{\prime}$ to rationally believe what $S$ thinks in T1 while doubting what $S$ thinks in $T 2$, or vice versa and (b) there is no difference in what $\mathrm{S}$ thinks in T1 and T2 other than what concepts of Q she employs.

Now, consider TW and a nonimagistic companion of TW such that the thinker has transparent and immediate knowledge that she's thinking about the same things in these two acts. (Henceforth, call such a thinking a nonimagistic transparent-samerefcompanion of $T W$.) Even if it's impossible for the subject of these two thinkings to rationally believe what she thinks in one while doubting what she thinks in the other, it may seem possible that some other subject does so. By CS2, it would then follow that what is thought in TW differs from what is thought in the nonimagistic transparent-sameref-companion of TW. In this way, it may seem possible to show, for any psychologically possible nonimagistic thinking, $\mathrm{x}$, that some subject could rationally believe what is thought in TW while doubting what is thought in $\mathrm{x}$, or vice versa, which would suffice to establish Imagism about Phenomenal Thought.

I think this strategy for defending Imagism about Phenomenal Thought fails as well. There are two problems with it. The first is that, while CS2 expresses a Fregean "cognitive significance" view of concept employment individuation, it does not provide a useful test for telling when a subject employs different concepts. The second is that, insofar as we can determine what one subject thinks in two acts on the basis of what attitudes another subject can rationally take, no reason for distinguishing the concepts employed in TW and a nonimagistic transparent sameref-companion of TW seems to emerge.

The reason CS2 is not a useful test for concept employment distinctness is that, in order to put it work one has to "pair up" the concepts employed by one subject with those employed by another. And that's not trivial to do.

The difficulty can be illustrated with the case in hand. Suppose a subject, $S^{\prime}$, thinks about some quality $\mathrm{Q}$ in two acts of thinking. In one act, she thinks about $\mathrm{Q}$ imagistically, in the other she does not. Call these thinkings TIS' and TNS' 
respectively. And suppose that, as it happens, $\mathrm{S}^{\prime}$ can rationally believe what she thinks in TIS' while doubting what she thinks in TNS', and that there is no difference between TIS' and TNS' other than what sensory quality concepts they employ. Then we can conclude that:

(P1) The concept of Q employed by $\mathrm{S}^{\prime}$ in $\mathrm{TIS}^{\prime} \neq$ the concept of Q employed by $\mathrm{S}^{\prime}$ in $\mathrm{TNS}^{\prime} .{ }^{30}$

Now, what we wanted was to use the facts concerning $\mathrm{S}^{\prime}$ to draw a conclusion about what another subject, S, thinks in a well-chosen imagistic thinking TW and a nonimagistic transparent-sameref-companion of TW; in particular that:

(C) The concept of Q employed by S in TW $\neq$ the concept of Q employed by $\mathrm{S}$ in a nonimagistic transparent-sameref-companion of TW.

But it's clear that (P1) by itself doesn't justify (C). The fact that the sensory quality concept that $\mathrm{S}^{\prime}$ employs in an imagistic thinking differs from the sensory quality concept she employs in a nonimagistic thinking goes no way, by itself, toward showing that what the other subject, $\mathrm{S}$, thinks in an imagistic thinking differs from what $\mathrm{S}$ thinks in a nonimagistic thinking. ${ }^{31}$

It's also clear what more we need. To move from (P1) to (C), we need to "pair up" the concepts employed in TIS' and TNS' with those employed in TW and its nonimagistic transparent-sameref-companion. In particular, we would have reason to embrace $(\mathrm{C})$, if in addition to (P1) we could establish that:

\footnotetext{
${ }^{30}$ The idea here is, of course, that (P1) is supported by a Single Subject Test for Concept Employment Distinctness, such as CS1. Note that we have not said that it is psychologically impossible for $\mathrm{S}^{\prime}$ to think nonimagistically what she thinks in TIS'. (That claim would amount Imagism about Phenomenal Thought.) That (i) S' employs different concepts in TIS' and TNS' is, for all that's been said, compatible with (ii) there being a third thinking, which in nonimagistic, and in which $\mathrm{S}^{\prime}$ employs the same concepts as in TIS'. (This trio may be exemplified by an imagistic thinking that I express as "that's my favorite quality", a nonimagistic thinking that I express as "Aunt Brenda's favorite quality is my favorite quality", and a nonimagistic transparent-sameref-companion of the first, imagistic thinking.)

${ }^{31}$ Nor even does it show that what $\mathrm{S}^{\prime}$ thinks in a third nonimagistic thinking differs from what she thinks in TIS'; see the previous footnote.
} 
(P2) The concept of Q employed by $\mathrm{S}^{\prime}$ in TIS' = the concept of Q employed by $\mathrm{S}$ in $\mathrm{TW}$.

(P3) The concept of Q employed by $\mathrm{S}^{\prime}$ in $\mathrm{TNS}^{\prime}=$ the concept of Q employed by $\mathrm{S}$ in a nonimagistic transparent-sameref-companion of TW.

But how do we justify the conjunction of (P2) and (P3)? It is clear that CS2, at least, does not provide any help here. CS2 tells us that what one subject thinks in two acts of thinking is under certain conditions not the same. What we need here are conditions under which two different subjects think the same thing.

Now, insofar as we can make progress on comparing the concepts employed by $\mathrm{S}^{\prime}$ and $\mathrm{S}$ in the present case, it seems to me hopeless to find support for both (P2) and (P3). There may be some prospects of defending (P2). If one and the same quality is considered at the same level of specificity in TIS' and TW, that might be reason enough to endorse this claim. But it's hard to see that any reason to accept (P3) is forthcoming. TNS' and a nonimagistic transparent-sameref-companion of TW play very different roles in the cognitive lives of their respective subjects: it is not clear to the subject of TNS' that the quality she thinks about in this act is the same quality that she thinks about in the imagistic thinking TIS'. (For, by hypothesis, she can rationally doubt what she thinks in TNS' while believing what she thinks in TIS', and there is no difference in what she thinks in these acts other than what sensory quality concept of Q she employs. And there would seem to be room for such rational divergence of attitudes only when it's not clear to the thinker that she thinks about the same quality in the two acts.) By contrast, it is transparently and immediately clear to the subject of a nonimagistic transparent-sameref-companion of TW that the quality she thinks about in this act is the same quality she thinks about in TW. In view of this difference between TNS' and a nonimagistic transparent-sameref-companion of TW, I see no room for optimism about defending (P3). ${ }^{32}$

\footnotetext{
${ }^{32}$ One may be mislead into supposing that CS2 provides a way to distinguish what is thought in TW and a nonimagistic transparent-sameref-companion of TW by a similarity between this (proposed) procedure and a procedure that does enable us to distinguish what a subject $\mathrm{S}$ says on two occasions on the basis of what attitudes another subject, $\mathrm{S}^{\prime}$, might rationally take to $\mathrm{S}^{\prime} \mathrm{s}$ utterances. Thus, consider this test:
} 
I have considered two Fregean tests for concept employment distinctness. I can't, of course, consider every such test that has been formulated or may be motivated. But even without doing so, I think we have grounds for generalizing to the conclusion that there is no reasonable Fregean cognitive significance test that supports Imagism about Phenomenal Thought; or at least, that this is so as long as we consider fairly generic sensory qualities. Imagism about Phenomenal Thought says that there is a concept (of some quality Q) that we sometimes employ while we experience Q and that we can employ only while we experience Q. The discussion of CS2 provides reason, it seems to me, to suppose that no Multiple Subject Test for Concept Employment Distinctness can be used to support this. And, given Observation, it seems reasonable to suppose that no Single Subject Test for Concept Employment Distinctness can support this either. According to Observation, whenever a subject thinks imagistically about some sensory quality $\mathrm{Q}$, it is possible that that subject also thinks nonimagistically about $\mathrm{Q}$ and has knowledge that she thinks about the same quality in these two acts which is no more fallible or inferential than the best knowledge we can ever have that two thinkings concern the same thing. Provided that this is right, it is reasonable to expect that, if some cognitive significance-test were to distinguish the sensory quality concepts that are employed in two such acts, then that test would imply that we can't ever employ the same concept twice. Assuming that this conclusion should be

CS3: Two tokens of different public language sentence-types, E1 and E2, used by a speaker $\mathrm{S}$ of a language $\mathrm{L}$, semantically express different things if it's possible for some competent user $\mathrm{S}^{\prime}$ of $\mathrm{L}$ to rationally assent to some token of E1 while dissenting from some token of E2, or vice versa.

(CS3 resembles one formulation that Evans (1982, 18-20) gives of his "Intuitive Criterion of Difference" for thoughts. However, I think there are suggestions of all of CS1-CS3 in these pages.) Now, take the sentences 'Detroit is an American city' and 'Motown is an American city'. Many of us know that these sentences concern the same things. Given this knowledge, we arguably can't rationally assent to one of them while dissenting from the other (cf. Evans 1982, 19). However, if one adopts $\mathrm{CS} 3$, one can still distinguish what the two sentences semantically express - even in our mouths - on the ground that some subject could be competent with both of them and rationally assent to one while dissenting from the other. I think it is of considerable interest to explore why we can't in an analogous way distinguish with the aid of CS2 what one subject thinks in an imagistic thinking TW and a nonimagistic transparent-sameref-companion of TW. The issue seems to me complex, and I can here offer just a pointer. I believe the explanation lies in two related differences between the cases. The first is that, while the typing of public language symbols is largely independent of speakers' cognitive perspectives, the typing of inner symbols (if there are such) is not clearly independent of thinkers' cognitive perspectives. The second difference is that the kind of transparent and immediate knowledge of co-reference that is available to us (in the first person) in the case of thinking, is not available to us (even in the first person) in the case of different public language terms like 'Detroit' and 'Motown'. 
rejected, any test that individuates concept employment so finely as to yield it should be rejected too.

\subsection{Kinds of nonimagistic thinking about sensory qualities}

My main strategy in this paper is to examine and respond to considerations that might seem to support Imagism about Phenomenal Thought, thereby arguing that there is no good reason to accept the view. However, it seems fair to ask that I provide a somewhat more substantial idea - beyond the bare bones sketch in section 3.3 - of how Imagism about Phenomenal Thought could be false. In particular, one might want to know more about what kind - or kinds - of nonimagistic thinking could possibly amount to employment of the same sensory quality concept as a (wellchosen) imagistic thinking. ${ }^{33}$

Here is one way of articulating this request against the background of Fregean cognitive significance tests. It is clear that I can think nonimagistically about the sensory quality red by thinking about it "via" some other property. For example, I can think nonimagistically about red if I think something that is aptly expressed by a description like "Aunt Brenda's favorite quality". But presumably, what I think in all such cases can be distinguished, on Fregean grounds, from what I think in a wellchosen imagistic thinking concerning red where I think about the quality more directly. Thus, if Imagism about Phenomenal Thought is unacceptable even given a Fregean test for concept employment distinctness, there has to be some way of thinking about the sensory quality red that (i) is normally available to us, (ii) is nonimagistic. and (iii) does not amount to thinking about red "via" some other property. But what might the character of such a thinking be?

I don't wish to commit myself to any particular account of this here. But I shall present a package of suggestions that strikes me as attractive.

\footnotetext{
${ }^{33} \mathrm{I}$ 'm indebted to an anonymous referee for pressing me on this issue.
} 
To begin with, there appears to be a way of thinking about red that engages or draws upon a thinker's knowledge or understanding of how red looks, and that is therefore available to those and only those who know or understand this. One way to bring this knowledge or understanding into view is to note its independence of knowledge of other uniquely identifying facts concerning red: it seems in principle possible that a subject knows or understands how red looks (for example on the basis of having seen red), but has forgotten all other uniquely identifying facts she ever knew about the quality; so she doesn't know, for example, that it is the quality called 'red', or that it is the quality one typically experiences when one sees ripe tomatoes, or that it is the quality she experienced on this or that occasion in the past.

It seems to me plausible that (1) this kind of knowledge or understanding of how red looks is sometimes engaged while we experience red, and also that (2) we sometimes engage or draw upon it when we don't experience red (even in the broad sense of "experience" employed here); consider for example cases where one understands that someone who speaks about "red" speaks about the quality that looks a certain way, and other "passing", nonimagistic thinkings about this quality. Further, it seems that (3) when we engage or draw upon this knowledge to think about the quality red, we don't think about the quality "via" some other property; we think about it more directly than that, whether or not we experience the quality at the time. ${ }^{34}$ The plausibility of (1)-(3) lead me to think that a somehow activated knowledge or understanding of how red looks is a good candidate for a "cognitive component" that occurs in imagistic thinkings about red, and can also occur in nonimagistic thinkings about red, and which is such that its presence can suffice to think in the nonimagistic case the same thing that one thinks in the imagistic case (cf. section 3.3 above).

This strikes me as credible as far as it goes. However, I don't think it provides a complete picture of how nonimagistic thinkings and (well-chosen) imagistic thinkings can amount to employments of the same concepts. To appreciate one way in which the proposal is arguably incomplete, consider very specific sensory qualities. It seems plausible (to me) that I can think imagistically about such qualities. But it's doubtful

\footnotetext{
${ }^{34}$ For partly overlapping remarks about nonimagistic thinkings that have a close connection with imagistic thinkings, see Crane 2005, 156, 160-1; Papineau 2007, sect. 1, 2.4, and 4.2; and Chalmers 2003 , sect. 3.2, point 3 .
} 
that I can think nonimagistically what I think in such an act merely by drawing on the knowledge or understanding I have of how specific qualities appear. The problem is that I seem not to be able to determine any particular specific quality merely by drawing on this knowledge or understanding.

Given this limitation in nonimagistic thinking, how could a nonimagistic thinking amount to employment of the same concept as a well-chosen imagistic thinking concerning a very specific quality? One possibility is that this can be accomplished by somehow "connecting" a nonimagistic thinking to an imagistic one. One can conceive of this on the analogy of the linguistic "ditto". By connecting a "ditto" to another utterance, we can repeat the content of that utterance without reproducing its format. The present proposal is that we can similarly re-think, nonimagistically, what was thought in an imagistic thinking by connecting the nonimagistic thinking to the imagistic one.

Of course, the relevant "nonimagistic ditto" could hardly just "defer blindly" to what was thought in its imagistic companion; such blind deferring would amount to thinking about a quality somehow "via" the property of being the object of a certain mental act, and we could plausibly separate the thought contents of two such acts on Fregean grounds. To account for imagistic-nonimagistic same-thinking in the case of very specific qualities, it seems that a "nonimagistic ditto" would have to involve not only a memory of the imagistic act it connects with, but also a memory, and hence an understanding of what was thought in that act.

There are linguistic cases that have this character. Suppose for example that you listen to a long speech, and comprehend all parts of it as it proceeds. (Or perhaps even better, suppose that you yourself produce such a speech.) When the speech is over, you may be unable to repeat it verbatim. You may even be unable to repeat exactly what it said in any terms other than "ditto". But you don't merely remember the speech event; you also have a good grasp of what it said. To that extent, you can "ditto" non-blindly.

It seems to me, from reflection on my own case, that I can and sometimes do think nonimagistically about very specific sensory qualities by in some such way 
connecting to a prior imagistic thinking while engaging both a memory of the thinking, and a memory and hence an understanding of what was thought in it. For example, I once (and just once) saw and admired a deep red northern light. Right now the quality I then experienced is not experientially present to me. But I can think back at that quality, remembering both the perceptual event and - to some extent - the visual character of the quality. To the extent that I still remember and understand how that quality appeared, the "nonimagistic ditto" that I connect to the original event is non-blind.

The kind of "connection" between thinkings that I have tried to illustrate here need of course not be limited to imagistic and nonimagistic thinking concerning very specific sensory qualities. It may well occur between thinkings concerning fairly generic qualities. For that matter, it may well occur when I think that "Detroit is an American city" and an instant later make the effort to think the same thing again. ${ }^{35}$

Let me bring together the package that emerges from this. The suggestion is that there are (at least) two basic ways in which a nonimagistic thinking regarding a quality Q can amount to employment of the same concept as an imagistic thinking concerning Q. First, this can be achieved in virtue of the fact that that the imagistic thinking and the nonimagistic thinking activate the same knowledge or understanding of how a quality appears. Second, it can be achieved in virtue of the fact that the nonimagistic thinking "connects" to the imagistic thinking, while engaging both a memory of that thinking and some degree of memory of what was thought in it. Both kinds of imagistic-nonimagistic same-thinking may well be available in the case of fairly generic qualities, but it seems likely that only the latter kind is available in the case of very specific qualities.

It's worth noting that, if this is right, there may well be ways of achieving imagisticnonimagistic same-thinking by combining the two basic mechanisms just described, constancy of understanding and connection between thinkings. Suppose that two imagistic thinkings, TI1 and TI2, both engage the same experienced quality-type Q

\footnotetext{
${ }^{35}$ There is some similarity between the present remarks about "connections" between thinkings and remarks about "strict co-representation" and "coordinated contents" that play a central role in Fine 2007.
} 
and the same understanding of how Q appears. One can reasonably suggest that, partly in virtue of engaging the same understanding, TI1 and TI2 amount to employment of the same sensory quality concept. Now suppose a nonimagistic thinking, TN, amounts to employment of the same sensory quality concept as TI1 by "connecting" with TI1 in the right way. Assuming that same-thinking is transitive, it follows that TN and TI2 are same-thinkings too. Note that, while such a case of same-thinking would require that one remembers TI1 at the time of TN, it wouldn't require that one remembers $T I 2$ at the time of TN - TI2 could even occur after TN. To that extent, the present proposal allows that there may be a certain "cognitive space" between an imagistic thinking and a nonimagistic thinking, even if these are same-thinkings and the same-thinking is achieved (in part) in virtue of a "connection" between thinkings.

Please note that I have not in this section tried to show that we can nonimagistically think whatever we think in some (well-chosen) imagistic thinking. I have just provided some suggestions about how such same-thinking could be achieved. For all that's been said, there might still be some good reason to suppose that we can't in fact achieve such same-thinking. I now return to examining whether there is any such reason.

\subsection{Specific qualities and the recognition argument}

Section 3.4 discussed thoughts about fairly generic qualities. I shall now consider whether Imagism about Phenomenal Thought can be supported by appeal to more specific sensory qualities. The following argument might seem to support the view.

Suppose I experience some highly specific sensory quality-type Q on two different occasions, let's say at $11.59 .30 \mathrm{pm}$ and $00.00 .30 \mathrm{am}$ on the next New Year's Eve. It would seem that, while I experience Q at 00.00.30, I can think about it in various ways. On the one hand, it seems that I can then think about Q imagistically. But it would also seem that there are various ways in which I can think about Q nonimagistically by "drawing" on my encounter with it at 11.59.30. For example, I 
may be able to demonstrate Q "through memory", or think about it via some description like "the quality I experienced at 11.59.30".

If this is right, then I can at 00.00 .30 think truly what we may represent as follows:

(1) My experiences during 2012 include an experience of ... [Q, imagistically conceived].

and I can at that time, 00.00.30, also think truly what we may represent as follows:

(2) My experiences during 2012 include an experience of ... [Q, nonimagistically conceived by drawing on my encounter with it at 11.59.30].

Conventions: The ordered pairs inside the square brackets represent, first, what my thought concerns - Q - and, second, my "way of directing my mind" at it respectively. The unfilled dots represent that we have yet to determine exactly what I think in this case; specifically, whether I may employ the same concept, or necessarily employ different concepts when I think about $\mathrm{Q}$ in these different ways. ${ }^{36}$

It would seem that I can rationally believe (1) while doubting (2). At 00.00.30, I may well not be able to tell that the quality-type I currently experience is the exact same one that I experienced a minute earlier. And it would seem that this recognitional limitation is compatible with my being fully rational.

If so, we have an argument that I employ two different concepts of Q in (1) and (2). I can rationally believe (1) while doubting (2). And presumably the only difference between (1) and (2) is the concept employment represented by the unfilled dots. Given our test CS1, we can then infer that the concept of Q that I employ when I conceive of Q imagistically at 00.00.30 differs from the concept I employ when I conceive of Q nonimagistically at 00.00 .30 , even though I think about the same quality in these thinkings.

\footnotetext{
${ }^{36}$ Recall that, as section 3.1 illustrated, a difference in my "way of directing my mind" at something need not correspond to a difference in concepts employed.
} 
Moreover, it would seem that the argument can be generalized. Even when we try our best, we are quite bad at telling whether a currently experienced quality-type is exactly the same as, or slightly different from, a quality-type experienced in the past no matter how near that past is, and no matter how we "draw" on the past encounter to think about the quality. It therefore seems that there will always be room for us to rationally believe something concerning a highly specific quality that we currently conceive imagistically while doubting the same thing about the same quality as conceived nonimagistically by drawing on a past encounter. Given a Fregean cognitive significance-test for concept employment distinctness, we can then infer that it is psychologically impossible for us to employ the same concept of a highly specific quality in two such thinkings. Call this the recognition argument.

It might perhaps seem as if the recognition argument provides a persuasive case for Imagism about Phenomenal Thought. ${ }^{37}$ However, any such appearance dissolves on reflection, as I shall now try to show. In the first place, even if the argument should successfully establish its conclusion, it does not thereby establish Imagism about Phenomenal Thought, because its conclusion does not amount to Imagism about Phenomenal Thought. In fact, reflection on the argument reveals that no appeal to our recognitional limitations can by itself provide a case for Imagism about Phenomenal Thought. One might perhaps suggest, in response to this, that the recognition argument can still take us a significant step towards Imagism about Phenomenal Thought. But I shall go on to argue that not even that is correct.

The recognition argument considers a situation in which a specific quality-type $\mathrm{Q}$ is conceived both imagistically and nonimagistically and where these two thinkings

\footnotetext{
${ }^{37}$ Thau $(2002,218)$ spells out something like this argument in the course of arguing for Imagism about Phenomenal Thought (or, more specifically, in the course of arguing for a view on perception and belief that according to Thau requires or motives Imagism about Phenomenal Thought). In the end, Thau refrains from relying on his recognition argument. If I understand him right, he distances himself from it because of it relies on a contingent feature of us (ibid., 220). This is indeed a clear limitation of any such argument: it is surely possible that some thinker could reliably recognize even very specific qualities as the same across time, and no argument along the above lines could establish anything of interest about such a thinker. But it's equally clear that this limitation does not prevent the argument from supporting the kind of anthropological view that is our present concern. Chalmers (2003, sect. 3.2 , point 3) alludes to our poor recognitional abilities of specific qualities in the course of articulating his view that there are "direct phenomenal concepts", which can be employed only while one has an
} 
"draw" on different experiential encounters with $Q$ : the imagistic thinking draws on the experiential encounter at 00.00.30 while the nonimagistic thinking draws on the preceding experiential encounter at 11.59.30. It concludes that it is psychologically impossible for us to employ the same concepts of Q in two such thinkings.

The kind of case that the argument considers and that its conclusion concerns is represented in figure 1, where TIQ represents an imagistic thinking concerning a quality Q, TNQ a nonimagistic thinking concerning Q, and the two EQ:s two different experiences of Q; the lines between thinkings and experiences represent which experiential encounter a thinking draws on. (The temporal order and temporal distance between the thinkings are immaterial for present purposes. The thinkings in question may be simultaneous or separated by a long or short period of time, and either one can occur before the other. What matters is that they draw on different experiential encounters.)

Insert figure 1.

Imagism about Phenomenal Thought makes a claim that is not restricted to this kind of case. It says that there is a sensory quality concept that we occasionally employ imagistically and that we can't employ nonimagistically at all. This claim covers, among other cases, those where a nonimagistic thinking draws on the same experiential encounter as an imagistic thinking, as when I think imagistically about a specific quality-type $\mathrm{Q}$ at a time $\mathrm{t}$, and then (say, a moment later) think about $\mathrm{Q}$ nonimagistically by drawing on the encounter at $t$. This kind of case is represented in figure $2 .{ }^{38}$

Insert figure 2.

experience. He does not spell out an argument, but might have something like the recognition argument in mind.

${ }^{38}$ Imagism about Phenomenal Thought covers other cases as well; for example, those where a nonimagistic thinking don't draw on any experiential encounter at all, as when I think about "the quality, whatever it might be, that I would experience if I were to view the back cover of this book". But the case represented in figure 2 is the most relevant for present purposes, since it most clearly presents a difficulty for Imagism about Phenomenal Thought. 
Since the recognition argument makes no claim about the latter kind of case, its conclusion does not amount to Imagism about Phenomenal Thought. Moreover, it seems clear enough that no interesting conclusion about this kind of case can be reached by appealing to our recognitional limitations. The reason is plain: in the kind of case where one twice thinks about a quality $Q$ by drawing on one and the same encounter with $Q$, the issue of recognizing that $Q$ has been encountered twice does not arise. Of course, this kind of case highlights the issue of (a) how one might know that two thinkings, that in fact both concern a specific quality $\mathrm{Q}$ and draw on one and the same experiential encounter with Q, both concern Q. But this issue is distinct from the issue of (b) how one might know that two different experiential encounters, that are in fact both experiential encounters with a specific quality Q, are both experiential encounters with Q. Our limited ability to reidentify qualities on the basis of experience constitutes a limitation with regard to the latter issue. But this limited ability has nothing to do with the former issue; or so it is safe enough to suppose, because the former kind of case does not involve reidentifying any quality on the basis of experience.

In response to this, one might propose that the recognition argument still takes us a significant step towards Imagism about Phenomenal Thought, because (i) it establishes that we necessarily employ different sensory quality concepts in a wide range of imagistic and nonimagistic thinkings concerning specific sensory qualities, namely, those thinkings that draw on different experiential encounters, and (ii) an imagist may well be able to supplement the recognition argument with reasons for supposing that we necessarily employ different sensory quality concepts in the remaining imagistic and nonimagistic thinkings, in particular those that draw on one and the same experiential encounter.

The remainder of this section will advance doubts about both (i) and (ii) in the above suggestion. Regarding (ii): even if the argument should be sound, there is reason to doubt that an imagist could supplement it in the proposed way. And regarding (i), there is reason to doubt that the argument is sound in the first place.

One reason to doubt that the recognition argument could be supplemented in the suggested way goes back to the claim: 
Observation: In any case where some normally functioning human subject thinks about some (fairly generic) sensory quality Q while experiencing $\mathrm{Q}$, it is psychologically possible for the person to (a) also think (say, a moment later) about $\mathrm{Q}$ without experiencing $\mathrm{Q}$, and (b) have transparent and immediate knowledge that she's thinking about the same quality in these two acts.

In section 3.4 I set aside whether this claim was true for the case of very specific qualities, because I didn't see a way of addressing the doubts one might have about this in an effective way at that point. However, we now have some means to do so.

Call the claim that Observation is true for the case of very specific qualities Observation Specific. Section 3.4 mentioned two things that might trigger doubt about this claim. One was that (a) it seems intuitively hard to hold very specific qualities "in mind" in the absence of experience of them. The other was that (b) we are poor at reidentifying such qualities on the basis of experience.

It seems to me that neither of these is a good reason to doubt Observation Specific. As I have tried to bring out, regarding (a), we can hold very specific qualities "in mind", even in the absence of experiences of them, in the sense that we can think about such a quality even in the absence of an experience of it; for example, by somehow or other drawing on a preceding encounter with it. And, regarding (b), the fact that we are poor at reidentifying such qualities on the basis of experience has (we may safely suppose) nothing to do with our ability to tell that two thinkings concern the same quality in the cases where the thinkings draw on one and the same experiential encounter. Therefore, as far as our abilities or inabilities to hold "in mind" or reidentify specific qualities are concerned, there is no apparent objection to supposing the following, which entails the truth of Observation Specific: In any case where some normally functioning human subject thinks about some very specific sensory quality $\mathrm{Q}$ while experiencing $\mathrm{Q}$ at a time $\mathrm{t} 1$, it is psychologically possible for the subject to think about $\mathrm{Q}$ at a later time, $\mathrm{t} 2$, without experiencing $\mathrm{Q}$ by drawing on 
the experiential encounter at $t 1$, and have transparent and immediate knowledge that she's thinking about the same quality in these two acts. ${ }^{39}$

I can't think of any other grounds to doubt Observation Specific. Therefore, I think the justification provided for Observation in section 3.4 extends to this case. And, if Observation Specific is correct, then, for the reasons given in section 3.4, there seems to be no hope of justifying Imagism about Phenomenal Thought by appealing to specific qualities. Or at any rate, there seems to be no hope of justifying this view by appealing to specific qualities and Fregean cognitive significance. To that extent, there is reason to doubt that an imagist can supplement the recognition argument with a case for holding that we necessarily employ different concepts in the kind of case represented in figure $2 .^{40}$

Furthermore, I think there is reason to doubt that the recognition argument is sound in the first place. The reason is that it arguably proves too much.

It's apparent that, whatever difficulty we have in determining whether an imagistic and a nonimagistic thinking concern the same quality-type $\mathrm{Q}$, if they draw on different encounters with Q, we also have in determining whether two imagistic thinkings concern $\mathrm{Q}$, if they draw on different encounters with Q. This is apparent because the difficulty is one and the same in both cases, to wit: to determine whether

\footnotetext{
${ }^{39}$ It is plausible that there are some senses in which we can't hold very specific qualities "in mind" in the absence of experiences of them. For example, it may well be psychologically impossible for us to intentionally image (for example visualize) sensory qualities at the level of specificity that we can experience them in veridical perceptions. But unless one assumes some imagistic view, it is hard to see how this (presumed) fact, which concerns a limitation in our imaging abilities, could provide reason to doubt Observation Specific, which concerns our abilities to think and to have a certain kind of knowledge about what we think. Another sense in which we plausibly can't hold very specific qualities "in mind" in the absence of experiences of them was noted in section 3.5: we arguably can't think about particular specific qualities merely by drawing on our knowledge or understanding of how they appear. But this again provides little reason to doubt Observation Specific. It tells us that there is one way in which we can't "reach down" in nonimagistic thinking to the level of specificity that we can reach down in imagistic thinking. But it doesn't rule out that there are other ways in which we can reach down in nonimagistic thinking to that level of specificity (section 3.5 offers a suggestion about how that might be achieved).

${ }^{40}$ What emerges from this is, I think, that from the point of view of defending Imagism about Phenomenal Thought, the recognition argument targets an easy case. Given our recognitional shortcomings, it is clear that we can't have transparent and immediate knowledge that an imagistic and a nonimagistic thinking both concern the same specific quality, if these thinkings draw on different experiential encounters. In this sense there is, for us, inevitably a "cognitive distance" between any two such thinkings. But it's hard to see why there should inevitably be the same cognitive distance between
} 
one has on two occasions experienced one and the same or two slightly different quality-types. Therefore, it seems clear enough that: if, on account of our poor recognitional abilities, there is always room for us to rationally take diverging epistemic attitudes to what we think in an imagistic and a nonimagistic thinking that draw on different experiential encounters with a specific quality $Q$, then there is always room for us to rationally take diverging epistemic attitudes to what we think in two imagistic thinkings that draw on different encounters with Q. And, if the possibility of rationally taking "diverging epistemic attitudes" to what one thinks in the relevant imagistic and nonimagistic thinkings is a good reason to suppose that we can't ever employ the same sensory quality concepts in two such thinkings, then the possibility of rationally taking diverging epistemic attitudes to what one thinks in the relevant imagistic thinkings should also be a good reason to suppose that we can't ever employ the same sensory quality concepts in two such thinkings. That's to say, if we accept the recognition argument, we should also accept that we necessarily employ different sensory quality concepts in any two imagistic thinkings that concern some specific quality $\mathrm{Q}$ and draw on different encounters with $\mathrm{Q}$ - which is presumably to say that we necessarily employ different sensory quality concepts in any two imagistic thinkings concerning specific qualities period.

I think this conclusion is unattractive, and not the least to an imagist about phenomenal thought. I propose to just assume this, since we are by now a rather long way from a strong case for Imagism about Phenomenal Thought. Assuming this, there is reason to reject the argument for the conclusion. But since this argument is on all essential points the same as the recognition argument, there is reason to reject that argument too.

One may of course wonder what could be wrong with the recognition argument - and its twin argument concerning imagistic thinkings. One can hardly question the facts about our recognitional limitations. But how can one resist the lines of reasoning from those facts to the conclusions concerning distinctness of concept employment? I shall conclude this section by mentioning three possible diagnoses of where the arguments go wrong; I shall not choose between these diagnoses.

an imagistic and a nonimagistic thinking that draw on the same experiential encounter with a specific quality. 
(i) One possibility is that the arguments are flawed already in their shared assumption that we can form the relevant concepts of highly specific sensory qualities. On this diagnosis, it is wrong to conclude that we necessarily employ different concepts in the relevant thinkings, because we can't employ the relevant concepts at all. $^{41}$

(ii) Alternatively, one might suggest that the arguments employ too liberal a conception of rationality. It is essential to the arguments that I can rationally take diverging epistemic attitudes to the relevant thinkings. This may seem plausible on the ground that the recognitional imperfections that lie behind such doubts are beyond our reflective control. But on the other hand, these recognitional imperfections are ours, and belong to our cognitive lives broadly conceived. And one could propose that rationality requires that one makes optimal use of all the information that is available to one, not just in reflective thought but towards the perceptual "periphery" as well. Since we fail this test in the relevant cases, there is according to this diagnosis not the right kind of "cognitive significance" ground for supposing that we necessarily employ different concepts in the thinkings under consideration. ${ }^{42}$

(iii) Finally, one may deny that the possibility of rationally taking diverging epistemic attitudes is - or is generally - a reliable test for concept employment distinctness. On a radical note, one may deny the whole idea of individuating concept employment on the basis of cognitive significance. More moderately, and closer to the Fregean spirit of the arguments, one may accept that concept employment be individuated by cognitive significance, but urge that in certain cases there can be sameness of cognitive significance (and hence of concept employment) despite a possibility of rationally taking diverging epistemic attitudes. ${ }^{43}$ On either version of this proposal, I

\footnotetext{
${ }^{41}$ This may be the view of some "nonconceptualists" about experience; see for example Kelly 2001. But I don't think one should suppose that all nonconceptualists claim or are committed to this.

${ }^{42}$ The diagnosis promotes a very demanding view of rationality. But in one respect it is less demanding than some currently embraced views. On the present proposal, rationality may still be an internal matter in the sense that: if I'm rational, so is any internal twin of mine. Rationality does not require that one be well-aligned with one's environment. For "externalist" views according to which rationality does require this, see Millikan 1993 and Williamson 2000.

${ }^{43}$ Some remarks made above suggest a way of developing the latter proposal. Take two imagistic thinkings, TI1 and TI2, that consider the exact same experienced quality-type at the exact same (fine) level of specificity. It seems somewhat natural to suppose that what is thought in TI1 has the same cognitive significance as what is thought in TI2, even if one can rationally take diverging attitudes to these thoughts. There is moreover some reason to suppose that, if a nonimagistic thinking, TN, is
} 
may be able to rationally take diverging epistemic attitudes to the relevant thinkings, but that does not entail that I employ different concepts in these acts.

\subsection{Holism about concept employment individuation}

I have so far, at some length, considered Imagism about Phenomenal Thought in view of Fregean "cognitive significance" tests for concept employment distinctness. In this section and the next, I shall, more briefly, discuss the prospects of defending Imagism about Phenomenal Thought given other tests for concept employment individuation.

As I mentioned in section 2.4, there is, besides "cognitive significance", one family of tests that is fairly widely embraced among contemporary philosophers and that is relevant for present purposes, namely holistic tests. Can Imagism about Phenomenal Thought be defended given some such test? I will consider one holistic test, which I hope to be representative enough:

The Holistic Test: Different concepts of a sensory quality-type Q are employed in two acts of thinking (concerning Q), T1 and T2, if there is some difference in what the subjects of $\mathrm{T} 1$ and $\mathrm{T} 2$ believe. ${ }^{44}$

It should be noted that this is a highly discriminating test. It entails, for example, that there is a concept of red that I can employ while I believe that some people walk their dogs on 45th street, but that I can no longer employ once I revise that belief. This seems, to me, to make the test rather unpalatable. But I shall set these doubts aside for present purposes, because I think that, even if this highly discriminating Holistic Test were adopted, there would be no reason to accept Imagism about Phenomenal Thought.

\footnotetext{
"connected" in the right way to TI, then the contents of TI and TN have the same cognitive significance (cf. section 3.5 and the discussion of Observation Specific in this section). Assuming that sameness of cognitive significance is transitive, the contents of TN and TI2 would then have the same cognitive significance as well, again even if one can rationally take diverging attitudes to them (cf. section 3.5). ${ }^{44}$ The "subjects of T1 and T2" may be either two different persons, or the same person at different times. Thus, the test can be applied both inter-personally and intra-personally.
} 
Take again a case where you find it most plausible that you apply some sensory quality concept that you can apply only while you experience the quality to which it applies. As before, call the chosen act of thinking TW (I shall suppose, arbitrarily, that it concerns the quality red). To use the Holistic Test in support of Imagism about Phenomenal Thought one has to make plausible that it is psychologically impossible to think about red without experiencing red and have the exact same beliefs that one has when one engages in TW. That is, there has to be either something one believes when one engages in TW but can't, as a matter of psychological necessity, believe when one doesn't experience red, or something one believes when one doesn't experience red but can't, as a matter of psychological necessity, believe when one engages in TW. But what might it be that one believes in one case but can't, as a matter of psychological necessity, believe in the other? If you start to search your mind, I think you will find that it is not easy to see what this might be.

As far as I can make out, it is reasonable to expect that, if there is reason to suppose that there is something I believe when I engage in TW but can't believe when I think nonimagistically about red, or vice versa, these reasons derive from something like the following "transparency principles":

Omniscience: It is psychologically necessary that: if I experience a sensory quality $\mathrm{Q}$ at a time $\mathrm{t}$, then $\mathrm{I}$ believe at $\mathrm{t}$ that $\mathrm{I}$ experience $\mathrm{Q}$ at $\mathrm{t}$.

Infallibility: It is psychologically necessary that: if I don't experience a sensory quality $\mathrm{Q}$ at a time $\mathrm{t}$, then I don't believe at $\mathrm{t}$ that I experience $\mathrm{Q}$ at $\mathrm{t}$.

These principles are not uncontroversial. ${ }^{45}$ But, again, I believe that even if one takes both of them on board, one will find it hard to make plausible that there is something I believe when I engage in TW but can't believe when I don't experience red, or vice versa.

\footnotetext{
${ }^{45}$ For doubt about Omniscience, see for example Tye 1995, 115, 190-1, and Block 1995, sect. 4.2.
} 
Suppose I engage in TW at $\mathrm{t} 1$, and then think about red without experiencing it a moment later, at $\mathrm{t} 2$. By Omniscience it follows that I believe at $\mathrm{t} 1$ that I experience red at $\mathrm{t} 1$ (or, as I may put it, "now"), and by Infallibility that I don't believe at t 2 that I experience red at $\mathrm{t} 2$. But this is of course compatible with my believing at $\mathrm{t} 2$ that $\mathrm{I}$ experienced red at $\mathrm{t} 1$ (or, as I may put it, "then"). It is also compatible with my believing at $\mathrm{t} 1$ that I will not experience red at $\mathrm{t} 2$. How then could one argue, on the basis of Omniscience and Infallibility that there must be some difference in what I believe at $\mathrm{t} 1$ and $\mathrm{t} 2$ ? The obvious strategy, I take it, would be to argue that what I believe at $\mathrm{t} 1$ and $\mathrm{t} 2$ about my experience at $\mathrm{t} 1$ - the beliefs that I would naturally express as "I experience red now" and "I experienced red then" - must be different. But I don't see that a good argument for this is forthcoming.

Note to begin with that there seems to be no prospect of using any holistic principle of belief individuation to justify that these two beliefs must be different. As far as holism goes, what I believe at $\mathrm{t} 1$ and $\mathrm{t} 2$ may well be exactly the same. An imagist who pursues the present line of argument would therefore have to find grounds beyond holism for distinguishing what is believed at $\mathrm{t} 1$ and $\mathrm{t} 2$. She might for this purpose try to invoke "cognitive significance". The suggestion would be that thought or belief contents are distinct if they are distinguished by either some cognitive significance test, or some holistic test. Equipped with these two complementary principles of content individuation, one might try to defend Imagism about Phenomenal Thought in two steps. In the first step one would argue, by appealing to cognitive significance, that if I believe at $\mathrm{t} 1$ that (as I may put it) "I experience red now" and at $\mathrm{t} 2$ that "I experienced red then", then I believe different things concerning the relevant point in time, $\mathrm{t} 1$. In the second step one would argue, by appeal to holism, that because I believe different things concerning $t 1$, at $\mathrm{t} 1$ and $\mathrm{t} 2$, I employ different concepts of red, when I think about that quality at those times.

This argument is theoretically inelegant, I think, appealing as it does to two different and unconnected principles of concept employment individuation. But I'm willing to set that issue aside as well. Even if, in addition to previous assumptions, we allow for this much theoretical inelegance, I don't see any prospect of justifying the first step of the argument. That is, I don't see any prospect of justifying, on the basis of "cognitive significance", that if I believe at t1 that (as I may put it) "I experience red now" and at 
t2 that "I experienced red then", then I employ different concepts of the point in time, t1. The most relevant consideration here is, I believe, an extension of the above Observation (section 3.4): It may well be transparently and immediately clear to me at $\mathrm{t} 2$ that the point in time that I then have a belief about (t1) is the same point in time I have a belief about at $\mathrm{t} 1$. This is, I think, undisputable. And, given this fact, I think that, for reasons that were spelled out at length in section 3.4 above, one can't use a cognitive significance test to argue that I inevitably believe different things concerning $\mathrm{t} 1$ at $\mathrm{t} 1$ and $\mathrm{t} 2$ respectively. ${ }^{46}$

In sum, it seems to me that I may well have exactly the same beliefs when I engage in TW and when I think about red without experiencing red. And if so, the Holistic Test can't be used to support Imagism about Phenomenal Thought.

\subsection{Other ways of individuating concept employment}

It is clear that there is some way of individuating concept employment such that, if it were acceptable, it would yield a sound argument for Imagism about Phenomenal Thought. Consider for example the following test:

The Imagistic Test: Different concepts of a sensory quality-type Q are employed in two thinkings $\mathrm{T} 1$ and $\mathrm{T} 2$ if $\mathrm{T} 1$ is an imagistic thinking about $\mathrm{Q}$ and $\mathrm{T} 2$ is a nonimagistic thinking about $\mathrm{Q}$.

If we accept this principle, we should accept Imagism about Phenomenal Thought. Indeed, we should accept the stronger, unqualified view that there is a concept we sometimes employ and that no possible subject could employ nonimagistically.

\footnotetext{
${ }^{46}$ Evans (1981, 307-8; 1982, 193-4) also argues that, as far as cognitive significance goes, what a subject thinks on a given day and would then naturally express as "Today is fine", may well be the same as what he thinks the day after and would then naturally express as "Yesterday was fine". But I believe Evans' argument for this is different from the one I give in the text. Note that the issue here is not whether the terms 'now' and 'then' have the same meaning, or express in the relevant contexts the same content. I have used these terms to indicate what I believe, but I think one should generally be wary of drawing conclusions about thought or belief contents on the basis of expressions used to report them (cf. Wettstein 2004, 130).
} 
However, I don't see what reasons there might be for adopting such a principle. It is sometimes suggested that we should be pluralists about concept employment individuation; that concept employment can and should be individuated in different ways for different purposes (see for example McGinn 1982, 210-1). Occasionally, one comes across an even more radical pluralism, namely that there are so many different purposes for which concept employment can be individuated that practically any way of doing it can be motivated. ${ }^{47}$ However, for reasons that have already been intimated (see sections 2.4 and 3.1), I'm doubtful of at least the latter, radical pluralism. Consider again the fact that I sometimes think that 15 is the square root of 225 in a meditative, brooding way, and sometimes in a casual, matter-of-fact way. Is there any purpose for which one would, on this basis alone, want to distinguish the concepts of 15 or square root or identity or 225 that are employed in two such thinkings? That's to say, is there any purpose for which one would want to adopt a principle to the effect that different concepts are employed in two thinkings T1 and T2 if T1 is meditative and brooding and T2 casual and matter-of-fact? I don't know that there is. And if there isn't, then it's not the case that any way of individuating concept employment can be motivated for one purpose or other. And if this is so, then, even if there are many useful ways in which one can individuate concept employment, one would still have to motivate that The Imagistic Test is or follows from one of them. And I don't see what the motivation for that might be.

It is of course possible that there is some test for concept employment individuation which both can be motivated and on the basis of which Imagism about Phenomenal Thought can be defended. But I'm unable to think of one. And I believe the sample of tests examined here provides reason to believe that tests for concept employment individuation will either (i) fail to support Imagism about Phenomenal Thought (like CS1, CS2, and the Holistic Test), or (ii) be hard to motivate (like the Imagistic Test), or (iii) both.

\footnotetext{
${ }^{47}$ I actually can't recall having seen this radical suggestion in print. But it has been mentioned to me though perhaps not wholeheartedly embraced - in conversation.
} 


\subsection{Mental Symbol Imagism again}

Before concluding, I'd like to make some brief and general remarks about the prospects of defending Mental Symbol Imagism, the view that there is a type of mental symbol 'Q' that we occasionally use to think about a quality $Q$ and that is psychologically impossible for us to use at a time unless we experience $Q$ at that time.

In one respect, it might be easier to defend Mental Symbol Imagism than Imagism about Phenomenal Thought: it might be easier to justify finer individuations of symbol-types than of their contents. To illustrate: It's not clear that there is any purpose for which one would want to say that two token words express different contents if one word is red and the other black. (This principle entails that any red token of 'and' and any black token of 'and' express different contents.) But there do seem to be purposes for which one would want to say that two token words belong to different types if one is red and the other black. (This principle entails that any red token of 'and' and any black token of 'and' are words of different types.) Consider for example the following generalization, which is true and useful, and which employs this typing: black words are readily detectable when placed against a red background, but red words are not. Assuming that we think with mental symbols, it might similarly be possible to justify finer individuations of these symbols than of the contents they "express". That would open a door for defending Mental Symbol Imagism, even if there is no good reason to accept Imagism about Phenomenal Thought.

This is not to say, however, that it is an easy task to defend Mental Symbol Imagism. A motivation for the relevant individuation of mental symbols would still have to be uncovered. Moreover, Mental Symbol Imagism occupies some controversial ground that Imagism about Phenomenal Thought avoids. Mental Symbol Imagism is true only if (i) experiences - or qualities experienced - sometimes figure as mental symbols, which is true only if (ii) we think with mental symbols at all. (ii) is controversial. And even among those who accept (ii), (i) is controversial. ${ }^{48}$

\footnotetext{
${ }^{48}$ For some relevant discussion, see Fodor 1975, 174-94. I'm not sure Fodor rejects (i), but he at least does not wish to commit himself to it, despite his firm attachment to (ii).
} 


\section{Concluding remarks}

I have argued that there is no good reason to accept Imagism about Phenomenal Thought. I have not - or not directly or explicitly - aimed for the stronger conclusion that Imagism about Phenomenal Thought should be rejected. I wish to make two brief remarks about how one could argue for that stronger conclusion, and what might be attractive about it.

(1) The negation of Imagism about Phenomenal Thought is that any sensory quality concept $Q$ (for a quality $\mathrm{Q}$ ) that we employ is such that we can employ it at a time without experiencing $\mathrm{Q}$ at that time. Call this the nonimagistic hypothesis. On the basis of the previous discussion, it is easy to outline, in general terms, an argument for this hypothesis. I have considered various tests for concept employment distinctness: tests that say, roughly, that if there is a relevant cognitive difference between two acts of thinking T1 and T2, then different concepts are employed in T1 and T2. Now, if there is a correct test of this kind - or a test of this kind which we for some purpose have reason to adopt - then there is presumably also a correct test - or a test which we for some purpose have reason to adopt - for concept employment sameness: a test that says, roughly, that if there is a relevant cognitive sameness between two acts of

thinking T1 and T2, then the same concepts are employed in T1 and T2. Observations made above provide ample material for defending the nonimagistic hypothesis on the basis of such a test. For example, suppose we were to accept that I employ the same concepts in two thinkings T1 and T2 if I can't rationally believe what I think in T1 while doubting what I think in T2. It should be clear that this test combined with observations made above would support the nonimagistic hypothesis.

(2) It seems to me that the nonimagistic hypothesis allows for a natural account of certain continuities in our cognitive lives. Suppose I attend to a red surface in front of me and think - as I may naturally express it - 'that surface is red', all the while being intensely aware that the quality I think about is the quality I experience. It seems to me natural to suppose that what I then think concerning the surface is something I can and often do remember and believe ("dispositionally" and nonimagistically) for an extended period of time. Further, it seems natural to suppose that what I thus 
remember and believe, I can and sometimes do recall ("occurrently"), either imagistically or nonimagistically. The nonimagistic hypothesis is compatible with all this. Imagism about Phenomenal Thought, in contrast, is not. Imagism about Phenomenal Thought rules out that what I at one point think imagistically I can remember and believe nonimagistically afterwards. ${ }^{49}$ And, while it allows that I may imagistically recall what I at an earlier time imagistically thought, it rules out that what I thus recall is the same as what I in the meantime remembered.

As I illustrated in the introduction, there is no doubt that experience in its various forms makes important contributions to our cognitive lives. But I don't think it makes the contribution that Imagism about Phenomenal Thought says. ${ }^{50}$

\section{References}

Alter, Torin, and Sven Walter, eds. 2007. Phenomenal Concepts and Phenomenal Knowledge: New Essays on Consciousness and Physicalism. Oxford: Oxford UP. Armstrong, David. 1973. Belief, Truth and Knowledge. Cambridge: Cambridge UP. Balog, Katalin. Forthcoming a. Acquaintance and the Mind-Body Problem. Online at http://pantheon.yale.edu/ kb237/Web\%20publications/Acquaintance.pdf.

- Forthcoming b. In Defence of the Phenomenal Concept Strategy. Online at http://pantheon.yale.edu/ kb237/Web\%20publications/PCS-Response.pdf.

Barsalou, Lawrence. 1999. Perceptual Symbol Systems. Behavioral and Brain Sciences 22: 577-609.

Berkeley, George. 1710/1988. A Treatise Concerning the Principles of Human Knowledge, edited by Jonathan Dancy. Oxford: Oxford UP.

\footnotetext{
${ }^{49}$ Imagism about Phenomenal Thought allows, of course, that the content of my original (imagistic) thinking and the content of my later (nonimagistic) memory may concern the same "fact". But it entails that the contents I think and remember are distinct.

${ }^{50}$ Research on this paper has been supported by Riksbankens Jubileumsfond (RJ). I have presented portions of the material at the European Society for Philosophy and Psychology in Lund, CUNY Cognitive Science Symposium, and the Pacific APA in Portland. I have also discussed it in the Umeå philosophy seminar. I recall some especially helpful comments, on these and other occasions, from Jared Blank, Alex Byrne, Sten Lindström, Fiona Macpherson, Pete Mandik, Iris Oved, Anders Pettersson, David Rosenthal, Inge-Bert Täljedal, Mats Wahlberg, and Roger Wiberg. Special thanks to Ned Block, who provided me with a shower of potential considerations in favor of Imagism about Phenomenal Thought over a cup of coffee by Washington Square just as I began writing this. That
} 
Block, Ned, ed. 1981. Readings in Philosophy of Psychology, 2 vols. Cambridge, MA: Harvard UP.

1995. On a Confusion about a Function of Consciousness. Behavioral and Brain Sciences 18: 227-87.

. 2007. Max Black's Objection to Mind-Body Identity. In Alter and Walter 2007, 249-306.

Boghossian, Paul. 1994. The Transparency of Mental Content. In Philosophical

Perspectives 8: Logic and Language, edited by James Tomberlin, 33-50.

Atascadero, CA: Ridgeview.

Brewer, Bill. 1999. Perception and Reason. Oxford: Oxford UP.

Brown, Jessica. 2004. Anti-Individualism and Knowledge. Cambridge, MA: MIT Press.

Byrne, Alex. 2004. Perception and Conceptual Content. In Contemporary Debates in Epistemology, edited by Ernest Sosa and Matthias Steup, 231-50. Oxford:

Blackwell.

Campbell, John. 1987. Is Sense Transparent?. Proceedings of the Aristotelian Society 61: 273-92.

Chalmers, David. 2002. Sense and Intension. In Philosophical Perspectives 16:

Language and Mind, edited by James Tomberlin, 135-82. Oxford: Blackwell. 2003. The Content and Epistemology of Phenomenal Belief. In

Consciousness: New Philosophical Perspectives, edited by Quentin Smith and Aleksandar Jokic, 220-72. Oxford: Oxford UP.

Crane, Tim. 2005. Papineau on Phenomenal Concepts. Philosophy and Phenomenological Research 71: 155-62.

Dummett, Michael. 1973. The Philosophical Basis of Intuitionistic Logic. In Logic Colloquium '73, edited by H.E. Rose and J.C. Sheperdson, 5-40. Amsterdam: North-Holland. Page references are to the reprint in Dummett, Truth and Other Enigmas, 215-47. Cambridge, Mass: Harvard UP, 1978.

Evans, Gareth.1981. Understanding Demonstratives. In Meaning and Understanding, edited by Herman Parret and Jacques Bouveresse, 280-303. Berlin: De Gruyter. Page references are to the reprint in Evans, Collected Papers, 291-321. Oxford: Oxford UP, 1985. 
1982. The Varieties of Reference, edited by John McDowell. Oxford:

Oxford UP.

Field, Hartry. 1978. Mental representation. Erkenntnis 13: 9-61. Page references are to the reprint in Block 1981, vol. 2, 78-114.

Fine, Kit. 2007. Semantic Relationism. Oxford: Blackwell.

Fodor, Jerry. 1975. The Language of Thought. Cambridge, MA: Harvard UP. 1978. Propositional Attitudes. The Monist 61: 501-23. Page references are to the reprint in Block 1981, vol. 2, 45-63.

- 1987. Psychosemantics: The Problem of Meaning in the Philosophy of Mind. Cambridge, MA: MIT Press.

1994. The Elm and the Expert: Mentalese and its Semantics. Cambridge, MA: MIT Press. 1998. Concepts: Where Cognitive Science Went Wrong. Oxford: Oxford UP.

Fodor, Jerry, and Ernest Lepore. 1992. Holism: A Shopper's Guide. Oxford: Blackwell.

Frege, Gottlob. 1918/1997. Thought, In The Frege Reader, edited by Michael Beaney, 325-45. Oxford: Blackwell.

Hume, David. 1739/1978. A Treatise of Human Nature, edited by Peter Nidditch. Oxford: Oxford UP.

Jackson, Frank. 1982. Epiphenomenal Qualia. Philosophical Quarterly 32: 127-36. . 1986. What Mary Didn't Know. The Journal of Philosophy 83: 291-5. 2003. Mind and Illusion. In Minds and Persons, edited by Anthony O'Hear, 251-71. Cambridge, Cambridge UP.

Kant, Immanuel. 1781/1929. Critique of Pure Reason. London: Macmillan.

Kelly, Sean. 2001. Demonstrative Concepts and Experience. The Philosophical Review 110: 397-420.

Levin, Janet. 1986. Could Love Be Like a Heatwave? Physicalism and the Subjective Character of Experience. Philosophical Studies 49: 245-61.

Lewis, David. 1983. Postscript to 'Mad Pain and Martian Pain'. Philosophical Papers, vol.1., 130-2. Oxford: Oxford UP. 1988. What Experience Teaches. Proceeding of the Russellian Society 13: 29-57. 
Loar, Brian. 1990/1997. Phenomenal States. Originally published in Philosophical Perspectives, 4: Action Theory and Philosophy of Mind, edited by James Tomberlin, 81-108. Atascadero, CA: Ridgeview, 1990. Reprinted in substantially revised form in The Nature of Consciousness: Philosophical Debates, edited by Ned Block, Owen Flanagan, and Güven Güzeldere, 597-616. Cambridge, MA: MIT Press, 1997. Page references are to the 1997 version.

McGinn, Colin. 1982. The Structure of Content. Thought and Object: Essays on Intentionality, edited by Andrew Woodfield, 207-58. Oxford: Oxford UP. McDowell, John. 1994. Mind and World. Cambridge, MA: Harvard UP.

Melnyk, Andrew. 2002. Papineau on the Intuition of Distinctness. In SWIF Philosophy of Mind Review 4. Online at http://www.swif.uniba.it/lei/mind/forums/melnyk.htm.

Millikan, Ruth. 1993. White Queen Psychology; or, The Last Myth of the Given. White Queen Psychology and Other Essays for Alice, 279-363. Cambridge, MA: MIT Press.

Nemirow, Lawrence. 1980. Review of Mortal Questions, by Thomas Nagel. Philosophical Review 89: 473-477. 1990. Physicalism and the Cognitive Role of Acquaintance. Mind and Cognition: A Reader, edited by William Lycan, 490-9. Oxford: Blackwell. Papineau, David. 1993. Philosophical Naturalism. Oxford: Blackwell.

- 2002. Thinking about Consciousness. Oxford: Oxford UP.

_. 2007. Phenomenal and Perceptual Concepts. In Alter and Walter 2007, 11144.

Peacocke, Christopher. 1992. A Study of Concepts. Cambridge: MA: MIT Press. Prinz, Jesse. 2002. Furnishing the Mind: Concepts and Their Perceptual Basis. Cambridge, MA: MIT Press.

Quine, Willard Van Orman. 1960. Word and Object. Cambridge, MA: MIT Press. - 1990. Pursuit of Truth. Cambridge, MA: Harvard UP.

Stalnaker, Robert. 1984. Inquiry. Cambridge, MA: MIT Press.

Sacks, Oliver. 1995. The Case of the Colorblind Painter. In An Anthropologist on Mars: Seven Paradoxical Tales, 3-41. New York: Random House.

Sundström, Pär. 2008. Is the Mystery an Illusion? Papineau on the Problem of Consciousness. Synthese 163: 133-43.

Thau, Michael. 2002. Consciousness and Cognition. Oxford: Oxford UP. 
Tye, Michael. 1989. The Metaphysics of Mind. Cambridge: Cambridge UP. 1995. Ten Problems of Consciousness: A Representational Theory of the Phenomenal Mind. Cambridge, MA: MIT Press. 1999. Phenomenal Consciousness: The Explanatory Gap as a Cognitive Illusion. Mind 108: 705-25.

Wettstein, Howard. 2004. The Magic Prism. Oxford: Oxford UP.

Williamson, Timothy. 2000. Knowledge and its Limits. Oxford: Oxford UP.

Wittgenstein, Ludwig. 1953. Philosophical Investigations, edited by G.E.M. Anscombe and Rush Rhees, Oxford: Blackwell. 